NBER WORKING PAPER SERIES

\title{
URBAN WATER DISINFECTION AND MORTALITY DECLINE IN DEVELOPING COUNTRIES
}

\author{
Sonia R. Bhalotra \\ Alberto Diaz-Cayeros \\ Grant Miller \\ Alfonso Miranda \\ Atheendar S. Venkataramani \\ Working Paper 23239 \\ http://www.nber.org/papers/w23239 \\ NATIONAL BUREAU OF ECONOMIC RESEARCH \\ 1050 Massachusetts Avenue \\ Cambridge, MA 02138 \\ March 2017, Revised August 2018
}

We thank Marcella Alsan, Sebastian Bauhoff, John Briscoe, Jenna Davis, Günther Fink, Julio Frenk, Steve Luby, Jaime Sepulveda, Dean Spears, and Dan Smith for helpful comments and suggestions. We are grateful for excellent research assistance provided by Nina Brooks, Neesha Joseph, Satadru Mukherjee, Jenna Sherry, and Sonja Swenson. The views expressed herein are those of the authors and do not necessarily reflect the views of the National Bureau of Economic Research.

NBER working papers are circulated for discussion and comment purposes. They have not been peer-reviewed or been subject to the review by the NBER Board of Directors that accompanies official NBER publications.

(C) 2017 by Sonia R. Bhalotra, Alberto Diaz-Cayeros, Grant Miller, Alfonso Miranda, and Atheendar S. Venkataramani. All rights reserved. Short sections of text, not to exceed two paragraphs, may be quoted without explicit permission provided that full credit, including () notice, is given to the source. 
Urban Water Disinfection and Mortality Decline in Developing Countries

Sonia R. Bhalotra, Alberto Diaz-Cayeros, Grant Miller, Alfonso Miranda, and Atheendar

S. Venkataramani

NBER Working Paper No. 23239

March 2017, Revised August 2018

JEL No. H41,I18,J11

\section{ABSTRACT}

Historically, improvements in municipal water quality reduced mortality substantially in wealthy countries. However, water disinfection has not produced equivalent benefits in developing countries today. We investigate this puzzle by analyzing a large-scale municipal water disinfection program in Mexico that increased water chlorination coverage from 55\% to $90 \%$ within 18 months. On average, the program reduced childhood diarrheal disease mortality rates by $50 \%$. However, age (degradation) of water pipes and inadequate sanitation infrastructure attenuated these benefits substantially, ranging from no decline in cities with the worst infrastructure to $80 \%$ in those with the best - a decline consistent with historical experience.

Sonia R. Bhalotra

Department of Economics and ISER University of Essex

Wivenhoe Park

Colchester C04 3SQ

United Kingdom

srbhal@essex.ac.uk

Alberto Diaz-Cayeros

Freeman Spogli Institute for

International Studies

616 Serra St, C149

Stanford, CA 94305

albertod@stanford.edu

Grant Miller

CHP/PCOR

Stanford University

117 Encina Commons

Stanford, CA 94305-6019

and NBER

ngmiller@stanford.edu
Alfonso Miranda

Centro de Investigacion y Docencia Economicas

(CIDE)

Carretera México-Toluca

3655 Col. Lomas de Santa Fe 01210

México, DF México

alfonso.miranda@cide.edu

Atheendar S. Venkataramani

Massachusetts General Hospital

Harvard Medical School

50 Staniford $\mathrm{St}$

Boston, MA 02114

atheenv@upenn.edu 


\section{Introduction}

Historically, improvements in the quality of municipal drinking water made important contributions to population health in today's wealthy countries. Late nineteenth and early twentieth century investments in water purification led to substantial reductions in urban mortality in a number of countries, including Japan, France, Sweden, the United States, and the United Kingdom - in some cases, virtually eliminating waterborne disease (Cain and Rotella 2001; Cutler and Miller 2005; Ferrie and Troesken 2008; Ketzenbaum and Rosenthal 2014; Knutsson 2016; Koppaka 2011; Ogasawara and Inoue 2015; Preston and van de Walle 1978). These disinfection technologies were often introduced into relatively new municipal water systems with good quality pipes and sufficient supply to deliver water at full pressure without interruption (Melosi 2000).

Despite century-old knowledge about the benefits of water disinfection (Turneaure and Russell 1901), diarrheal diseases due to poor water quality remain prevalent in many low- and middle-income countries today. Worldwide, diarrhea is the second leading cause of child mortality (Liu et al. 2012; Vos et al. 2015) as well as a leading cause of morbidity (roughly 1.7 billion episodes per year) (Fischer Walker et al. 2013b). This disease burden persists despite the fact that cities in developing countries are using many of the same disinfection technologies that were historically successful (Bain et al. 2014; Ercumen et al. 2015; Gadgil 1998).

This study seeks to assess the effectiveness of water disinfection in developing countries, focusing on the case of Mexico - and importantly, to identify factors that limit the realization of their full potential. Recent literature on improving water quality in lowand middle-income countries has generally focused on interventions that are either small 
in scale or target rural populations with limited water system infrastructure (Arnold et al. 2013; Arnold and Colford 2007; Clasen and Haller 2008; Duflo et al. 2015; Gruber et al. 2013; Kremer et al. 2011; Zwane and Kremer 2007). However, the urban population is projected to reach nearly 2.5 billion worldwide by 2050 (United Nations Population Division 2014), and the rapid growth of cities will require larger-scale interventions focused on municipal water supply (Brown, Keath and Wong 2009; Fotso et al. 2007; McDonald et al. 2014; United Nations Development Programme (UNDP) 2006). The two studies (of which we are aware) examining interventions to improve urban water quality on a large scale are Galiani, Gertler, and Schargrodsky (2005), who show that privatization of municipal water companies in Argentina led to significant reductions in child mortality from water-borne diseases, and Greenstone and Hanna (2014), who find null effects of environmental regulation on water pollution in Indian cities. Rather than focus on ownership or regulation, we focus specifically on disinfection technology that is a cornerstone of urban water provision.

Improving urban water quality in developing countries on a large scale with proven disinfection technologies is difficult for many interrelated reasons. First, municipal water systems in many low- and middle-income countries are older, and thus subject to degradation. Pipe breaks and breaches allow even clean water to become contaminated (or re-contaminated) by bacterial pathogens in the surrounding soil (Lee and Schwab 2005; Shaheed et al. 2014). Low or intermittent water pressure in pipe networks can further reduce the efficacy of chlorination by increasing the degree of recontamination (Bhutta et al. 2013; Ercumen et al. 2015; Jeandron et al. 2015; Kumpel 
and Nelson 2013; Tokajian and Hashwa 2003). ${ }^{1}$ Both problems are compounded by the fact that repairing degraded infrastructure (or building new distribution networks) may be prohibitively expensive, and financing mechanisms (either through domestic capital markets or partnerships with multinational organizations) may be unavailable (Crocker and Masten 2002; Cutler and Miller 2006; Gadgil 1998; Masten 2011; United Nations Development Programme (UNDP) 2006). Second, improvements in water quality may not be effective without complementary investments in sanitation (Alsan and Goldin Forthcoming; Duflo et al. 2015). Third, the provision of improved water may weaken private incentives for protective health behaviors. Such compensatory behavior holds the potential to crowd-out the health benefits of water disinfection (Bennett 2012; Keskin, Shastry and Willis 2015).

A central contribution of our paper is that we study a massive nation-wide program to chlorinate municipal water systems across the entire country of Mexico within a single year. Moreover, because conditions across Mexico's municipalities varied widely at the time of implementation, we are able to isolate key factors governing program success (and failure) in improving health. Named Programa Agua Limpia (henceforth, PAL), this program was launched in 1991 in response to a cholera epidemic that swept rapidly through Central and South America (Gutierrez et al. 1996; Sepulveda et al. 2007; Sepulveda, Valdespino and Garcia-Garcia 2006). ${ }^{2}$ Within eighteen months,

\footnotetext{
${ }^{1}$ Unlike other disinfection technologies (like filtration, for example), residual chlorine remains in water from point of treatment to point of consumption. However, low or intermittent water pressure (on which data are not systematically available) increases the risk of recontamination as stagnant organic matter in the water supply effectively absorbs and reduces circulating chlorine levels. We thank Steve Luby for alerting us to this point.

${ }^{2}$ Notably, the baseline burden of diarrheal disease in Mexico around this time rivaled that of modern lowincome countries. For example, data from the Global Burden of Disease project demonstrate that there were 900 deaths per 100,000 post-neonates (1-12 month olds) in Mexico in 1990. In low-income countries the
} 
the number of localities disinfecting their water increased dramatically, from 250 to 15,000 , and the share of Mexico's population receiving disinfected water rose from 55\% to $90 \%$ (CONAGUA 1994). Importantly, clean water coverage was achieved without expanding existing piped water infrastructure or sewage networks.

To estimate the impact of PAL on child mortality across Mexico, we use detailed municipal-level mortality statistics by age and cause. While there was little variation in the timing of PAL implementation across regions, we are able to distinguish program effects on diarrheal disease deaths from potentially correlated omitted trends by using difference-in-difference approaches in which the "control diseases" are those not directly influenced by water quality. To further strengthen the identification of PAL program effects, we also estimate triple difference specifications, comparing changes in waterborne vs. control disease deaths across small- and medium-sized urban areas vs. large cities (population $>500,000$ ). This approach exploits the fact that PAL targeted small- and medium-sized population centers because water in larger cities was already chlorinated. In doing so, it also accounts for (minor) cholera prevention and treatment activities other than chlorination that were common across smaller towns and large cities - including legal restrictions on wastewater irrigation, hygiene campaigns, provision of Oral Rehydration Therapy (ORT), and general disease surveillance (CONAGUA 1994; Sepulveda et al. 2006). ${ }^{3}$

These different approaches yield substantively similar results. In general, our estimates suggest that PAL was associated with a $50 \%$ reduction in diarrheal disease

corresponding rate in 1990 was 1,300 per 100,000 and 500 per 100,000 in 2015. See http://ghdx.healthdata.org/gbd-results-tool.

${ }^{3}$ In practice water system chlorination was the overwhelming focus of the program (CONAGUA 1994). 
mortality rates among children under age 5, averting more than 28,000 deaths per year between 1991 and 1995 alone. These reductions were concentrated in the targeted smalland medium-sized cities. We estimate a cost per life year saved by PAL of $\$ 1,100$ (2015 USD). This suggests that the program was highly cost-effective by any standard. ${ }^{4}$ Our results are also robust to using different transformations of mortality rates, mortality counts rather than rates, different event study windows, and the inclusion of state-year fixed effects.

Motivated by the contrasting experience of wealthy countries in history and developing countries today, we then study municipal-level variation in program effects to investigate the circumstances under which large-scale municipal water disinfection in developing countries can be successful. First, we find that reductions in diarrheal disease mortality rates were not larger in urban municipalities with greater baseline piped water coverage rates. Because more extensive systems in Mexico are generally older, this result is consistent with engineering concerns about recontamination through degraded, aged infrastructure (Lee and Schwab 2005; Mazari-Hiriart et al. 2005; Tulchinsky et al. 2000) and reduced chlorine efficiency due to irregular water pressure and outages (Ashraf et al. 2017; Ercumen et al. 2015; Kumpel and Nelson 2013; Kumpel and Nelson 2014) - and we provide suggestive direct evidence in support of this hypothesis. Second, we find that the health benefits of clean piped water were greater in municipalities with more extensive sewage infrastructure. This finding is consistent with emerging evidence of

\footnotetext{
4 These estimates likely underestimate the true cost-effectiveness of PAL for two reasons. First, due to limitations in available cost data, we are only able to consider the period 1991-1995, but the health benefits of PAL presumably accrued far beyond this period. Second, recent studies show that clean water may have important effects on time allocation, financial transactions, and long-run human capital accumulation (Ashraf et al. 2017; Bhalotra and Venkataramani 2015a), but our calculation focuses entirely on survival benefits.
} 
complementarities between water disinfection and sanitation in the economics literature (Alsan and Goldin Forthcoming; Duflo et al. 2015), although it stands in contrast with null results found in the epidemiology literature (Fewtrell et al. 2005).

Simulations using the results suggest that childhood diarrheal disease mortality rates would have declined by $86 \%$ in urban areas nationwide if all municipalities had sewage coverage and new piped water infrastructure equivalent to the best performers in our sample - and at the cost of $\$ 641$ per life year saved. Notably, this degree of mortality decline is consistent with the historical health benefits of municipal water disinfection in developed countries.

Finally, we also use detailed household survey data to study if compensatory behavioral responses to water system disinfection played a role in attenuating program effects. We find that households in states benefitting more from PAL reduced their spending on bottled water, soaps, and detergents - private health investments that may substitute for clean piped water (Bennett 2012; Keskin et al. 2015). Notably, these reductions in household spending occurred only among households in small and mediumsized cities - precisely the areas targeted by PAL. Although we are unable to quantify the extent to which indirect health decrements due to these behavioral responses reduce program benefits, the degree of behavioral crowd-out appears to be far from complete.

Overall, our results have two broad policy implications. First, the average effects that we estimate for childhood waterborne deaths are large, suggesting that despite misaligned incentives and political manipulation that plague many state programs (Galiani, Gertler and Schargrodsky 2005; Greenstone and Hanna 2014), there is at least 
the potential for state-led initiatives to be impactful. ${ }^{5}$ Better understanding the political and organizational circumstances under which this is possible is a critical area for future research. Second, our finding that the effectiveness of urban water disinfection depends heavily on infrastructure quality - which is generally poor in developing countries suggests a potential role for improvements in financing and access to capital - through private-public partnerships or innovations in local public finance, for example (Crocker and Masten 2002; Cutler and Miller 2006).

The rest of this paper is organized as follows. Section 2 provides background on Mexico's clean water reform, Programa Agua Limpia, and Section 3 describes our data. Section 4 presents changes in waterborne disease death rates associated with PAL, Section 5 examines the circumstances under which public water quality investments are most effective, and Section 6 examines behavioral responses to program impacts. Section 7 presents estimates of the cost-effectiveness of PAL, and Section 8 then concludes.

\section{The History of Programa Agua Limpia in Mexico}

As in many developing countries, infectious diseases have historically been responsible for most of Mexico's burden of disease among children. During the 1980s, diarrheal diseases and acute respiratory infections were the two leading causes of child death, and diarrhea alone was responsible for nearly a quarter of deaths under age 5 (Gutierrez et al. 1996). Diarrheal mortality was concentrated in the poorer southern

\footnotetext{
${ }^{5}$ In fact, the average treatment effects we estimate are larger than found in Galiani, Gertler, and Schargrodsky (2005), who find that privatization led to an $8 \%$ decrease in child diarrheal disease mortality on average ( $26 \%$ in the poorest areas).
} 
region of Mexico (Figure 1), with rates in small and medium sized towns nearly twice as high as those in cities. ${ }^{6}$

In 1991, a cholera pandemic emerged in Chile and Peru and quickly spread through South and Central America (Medina 1991; Ries et al. 1992; Sepulveda et al. 2006). In an effort to limit its spread across Mexico, the Mexican Ministry of Health and the newly created National Water Commission (Comision Nacional del Agua, CONAGUA) launched Programa Agua Limpia (PAL, or the National Clean Water Program) in April 1991 (Sepulveda et al. 2007; Sepulveda et al. 2006). PAL was in principle a multi-faceted campaign that included: (1) chlorination of previously untreated water sources; (2) restrictions on the use of wastewater for irrigation (an important component of Chile's efforts against cholera (Medina 1991)); (3) health education campaigns targeting both the general population and health care providers; and (4) expansion of the availability of Oral Rehydration Therapy (ORT). ${ }^{7}$

Despite these multiple components, in practice, chlorination of municipal drinking water was the centerpiece of the program (CONAGUA 1994; World Bank 1994). Because larger cities (those with more than 500,000 inhabitants) already had established chlorination and filtration systems, PAL chlorination efforts targeted small and medium sized cities. In contrast, other (minor) program components were not specifically targeted to these areas and implemented more broadly (Sepulveda et al. 2006). Within 6 months of PAL's launch, the fraction of Mexico's population with

\footnotetext{
${ }^{6}$ Averaging over 1985-1990, the child diarrheal mortality rate in municipalities predominantly containing small towns and medium-sized cities was 7.76 deaths per 1,000 live births. In large cities (>1 million population), the corresponding mortality rate was 4.48 per 1,000 live births.

${ }^{7}$ Prior to the cholera pandemic, Mexico's primary approach to controlling diarrheal diseases emphasized treatment with ORT, which we discuss below, and clinical case management (Frenk et al. 2003)
} 
chlorinated piped drinking water rose from $55 \%$ (almost exactly the percentage of the

population living in large, previously chlorinated metropolitan areas) to 85\%. By 1994,

this figure exceeded $90 \%$ (Figure 2$).{ }^{8}$

Achieving these gains required a vast expansion of municipal water disinfection

through existing water pipe infrastructure. Nationwide, the number of water treatment

plants grew from 250 to nearly 15,000 , the number of residual chlorine monitoring

stations expanded from 200 to over 100,000 sites, and treatment capacity (the volume of

chlorinated water per unit time) doubled. In addition, to improve water quality in areas

without piped water coverage, chloride tablets were disseminated to households

(Sepulveda et al. 2006) and quality monitoring for commercial bottled water and ice was

expanded (CONAGUA 1994), although these efforts were secondary relative to

disinfection of water at the source. ${ }^{9}$

\footnotetext{
${ }^{8}$ Because implementation began in medium-size cities and then expanded to smaller towns, the increase in population coverage between 1991 and 1992 was much steeper than the corresponding increase in number of localities treated. Beginning in 1993, population coverage rose more slowly, but the number of localities treated continued to rise at the previous rate.

${ }^{9}$ Similarly, other components of PAL received substantially less emphasis and are also less likely to have had a meaningful impact on diarrheal disease mortality. For example, legal restrictions reduced the amount of farmland irrigated with wastewater (World Bank 1994). However, only a very small fraction of farmland was irrigated with wastewater prior to PAL $(\sim 0.1 \%)$ (CONAGUA 1994). Even if these crops were widely distributed, they are likely to have been in large cities as well as in small and medium-sized towns. Thus, we are able to account for this component of the policy in our triple difference models - see Section 4.1. Efforts to modify hygienic behavior included use of radio and television to disseminate messages about hand-washing and other sanitary practices (Sepulveda et al. 2006). However, experiences from other lowand middle-income settings suggest that their impact on diarrheal disease mortality is likely to be small, particularly in comparison with water system disinfection (Ahuja, Kremer and Zwane 2010; Dupas 2011). In addition to PAL-related efforts, two other potentially relevant programs are Programa Nacional de Solidaridad (PRONASOL), a nationwide anti-poverty program implemented between 1989-1994, and Programa Nacional de Agua Potable, Alcantarillado y Saneamiento (PAPAZU), for which Mexico received a \$300 million loan from the World Bank to expand access to potable water, sanitation, and sewage in the early 1990s (The World Bank 1995). However, these programs are unlikely to confound our analysis. PRONASOL-related potable water investments were generally focused in rural areas (Diaz-Cayeros and Magaloni 2003), which we exclude from our analysis. PAPAZU was small in scope: the 3.2 million individuals benefitting from PAPAZU (The World Bank 1995) represents only a fraction of the 30 million individuals who gained access to chlorinated water in the first year of PAL. PAPAZU activities were also concentrated in states (Estado de Mexico, Guanjanato, and Sonora) that had relatively lower burdens of diarrheal disease. Removing these states in our main regression models does not change our results.
} 
Prior work on PAL hints at large program effects. Gutierrez et al. (1996), Velazquez et al. (2004), and Sepulveda et al. (2006) show sharp declines in childhood diarrheal disease mortality rates beginning in 1991. Focusing on morbidity, Gutierrez et al. (1996) analyze changes in aggregate morbidity rates, showing that the average number of annual episodes of diarrheal disease morbidity among children decreased from 4.6 to 2.2 between 1990 and 1993. Similarly, Velazquez et al. (2004) show that morbidity declined by over 63\% during the period 1990-1995. However, these studies essentially only describe national trends over time.

\section{Data}

\subsection{Data}

Our core analyses use data from three sources: the Mexican Vital Statistics, the 10\% sample of the 1990 Mexican Population Census, and the Encuesta Nacional de Ingresos y Gastos de los Hogares (National Survey of Income and Expenditure, ENIGH). Mexican Vital Statistics. We use mortality data for neonates (age 0-1 months), post-neonates (1-12 months), and children (ages 1-4) from the Mexican Ministry of Health. The vital statistics contain individual-level records of every certified death in the country. ${ }^{10}$ Each death record contains information about the cause of death (coded using the International Classification of Diseases, $9^{\text {th }}$ Edition, or ICD-9), age at death, and

Finally, PAPAZU project reports reveal that many of the projects initiated as part of PAPAZU were deemed "out of compliance," and thus potentially of lower quality (The World Bank 1995).

${ }^{10}$ Certified deaths are all deaths that are brought to the attention of the National Statistics Office, Health Ministry, Judiciary, Military, and funeral directors. Certification, which includes coding of cause of death, is provided by an individual with a license to do so (typically a physician, nurse, or Health Ministry representative). 
municipality of death. Municipalities are the next administrative division below the state (analogous to U.S. counties).

We aggregate individual-level deaths for children under the age of 5 into municipality-cause-year cells for all municipalities and years between 1985 and 1995 . Given our focus on PAL, we create a category for infectious diarrheal diseases using three-digit codes from the International Classification of Diseases, Ninth Revision (ICD9). ${ }^{11}$ To convert diarrheal death counts into child (under-5), post-neonatal (1-12 months), and neonatal (0-1 month) mortality rates, we use data on the number of live births in each municipality and year. ${ }^{12}$ We compute average diarrheal mortality rates in the preintervention period (1985-1990) and trim the top and bottom $2.5 \%$ of municipalities in the distribution of this baseline rate (to account for outliers due to small population sizes). We also repeat our estimation using the full sample death counts instead of death rates, finding similar results (see Section 4.1 below).

A note about the quality of Mexico's vital statistics is also warranted. As in many developing countries, there are important concerns about under-reporting of deaths, particularly in poorer regions and among young children (Hernandez et al. 2012; LozanoAscencio 2008; Tome et al. 1997). ${ }^{13}$ Corrections for under-reporting and

\footnotetext{
11 We used ICD-9 codes 001-009 to identify deaths from infectious diarrhea. These codes cover intestinal infectious diseases and include cholera (001), typhoid and paratyphoid (002), salmonella infections (003), shigellosis (004), food poisoning (005), amoebiasis (006), protozoan causes (such as giardia and cryptosporidiosis, 007), infections due to other organisms (such as rotavirus and other viruses, 008), and presumed intestinal infection due to an ill-defined cause.

${ }^{12}$ We obtained municipality-year data on live births from the Instituto Nacional de Estadistica $y$ Geographia (INEGI http://en.www.inegi.org.mx/proyectos/registros/vitales/natalidad/). To compute mortality rates, we used a direct method (UNICEF et al. 2007) and divided the number of child deaths for a given cause-municipality-year by the number of live births in the same municipality-year (scaled to reflect the number of deaths per 1,000 live births).

${ }^{13}$ Hernandez et al. (2012) show that infant and child deaths may be underreported by as much as $20 \%$ in a sample of low human development index municipalities in 2008. However, it is important to note that in many instances birth certification might also underreport those children. In this case, the counts in the
} 
misclassification of deaths were made by the Ministry of Health from 1980 onwards, and these data have been used in other prominent studies, albeit at levels of aggregation above the municipality level (Barham 2011; Cutler et al. 2002; Foster, Gutierrez and Kumar 2009; Gonzalez and Quast 2011). In part because of these efforts, Mexico's Vital Registration system is now considered one of the best in the developing world in terms of completeness and quality (Mathers et al. 2005). We cannot rule out the possibility that some degree of underreporting remains, but for this to bias our results, underreporting and/or misclassification must have changed sharply in 1991, and differentially for diarrheal diseases relative to control diseases. ${ }^{14}$

1990 Mexican Population Census. We use the population census (a) to identify relevant municipalities (i.e., those targeted by PAL or those used for comparison) and (b) to obtain municipal characteristics for estimating heterogeneous PAL program effects. Using individual-level information on urban versus rural residence in a $10 \%$ sample of Mexico's 1990 population census (Minnesota Population Center 2015), we compute the proportion of each municipality's population living in rural areas (defined by the Mexican national statistical agency as towns with fewer than 2,500 inhabitants). We excluded from our sample 970 (of 2,394) fully rural municipalities for two reasons. First, PAL's chlorination efforts were concentrated in small- and medium-sized urban areas.

numerator and the denominator of reported mortality rates are under-counts and, in general, it is difficult to sign any resulting bias in the rates.

${ }^{14}$ The direction of any bias in the estimated treatment effect is a priori unclear. If improvements in measurement occurred across the board, then our use of differences with respect to control diseases will help account for bias from measurement error. However, it may be that recording of diarrheal disease mortality in particular improved with the introduction of PAL (via investments in diarrheal disease recognition and surveillance). This would bias downward our estimates of mortality rate changes associated with PAL. 
Second, as Section 2.1 notes, rural areas were targeted by other policies (and so excluding these areas removes their influence from our analysis).

To analyze heterogeneous effects of PAL across municipalities, we use household-level data from the 1990 census to create aggregated municipal-level measures of the share of households with piped water and the share of households with septic system connections in their dwelling (a measure of sanitation coverage). Additionally, we create measures of average earned income among adults; the fraction of adults completing secondary schooling; and the fraction of the population speaking an indigenous language. We use the 1960 and 1990 census microdata to compute measures of piped water system age.

Encuestas Nacional de Ingresos y Gastos de los Hogares (National Survey of Income and Expenditure, ENIGH). To study behavioral responses to PAL, we use the ENIGH, a nationally representative income and expenditure survey. These data include detailed information about expenditures on bottled water, soaps, and detergents, which we combine into a single category. We use the 1989, 1992, and 1994 waves, which are the only waves falling within our study period.

Table 1 shows descriptive statistics for all variables used in our analyses.

\subsection{Graphical Evidence}

Figure 3 shows trends in child (under age 5) mortality rates from diarrheal diseases and "control" diseases between 1985 and 1995 in urban municipalities using unadjusted data. We use two sets of control diseases to assess the sensitivity of our results to the choice of control illnesses. These are respiratory infections and non-infectious childhood diseases, respectively. The controls satisfy the condition that they are 
quantitatively important infectious causes of child mortality and are not directly

influenced by water quality. We discuss the control diseases in more detail in Section 4.1.

There is a downward trend in diarrheal disease mortality rates among children

under-5 prior to 1991 , which is widely attributed to Mexico's Oral Rehydration Therapy

(ORT) program that began in November 1984 (Gutierrez et al. 1996; Mota-Hernandez

and Velasquez-Jones 1985; Sepulveda et al. 2006). However, coincident with the

implementation of PAL, in 1991, the decline becomes distinctly more rapid and

pronounced. In contrast, there is no such trend break in mortality rates from the control

diseases. ${ }^{15,16}$ Importantly, trends in diarrheal and respiratory disease mortality rates prior

to PAL were quite similar. Appendix Figure 1 shows trends over a longer period of time

(1979-1997), and again the trend break in diarrhea-related mortality rates relative to

control disease mortality rates remains clear.

\section{Water Disinfection and Diarrheal Disease Mortality Rates}

\subsection{Empirical Strategy}

To formally estimate the relationship between PAL and mortality rates among

children under-5 (altogether, as well as separately for neonates (0-1 month), post-

\footnotetext{
${ }^{15}$ We formally test for a structural break between 1985-1995 in a longer series of data (1979-1997, Appendix Figure 1) using the Quandt Likelihood Ratio test (Quandt 1960). This test treats as agnostic the exact break point in a time series and calculates the $F$-statistic on different user specific break points window. The largest $F$-statistic across tests of different time points is used to identify the break point. For diarrheal diseases, examining each year between 1987-1994 as potential break points, the test identifies a break in 1991, coincident with the start of PAL $(F=11.16, \mathrm{p}=0.004)$. We do not find evidence of a statistically significant break over the same period for either set of control diseases.

${ }^{16}$ Notably, in the years just prior to PAL, the narrowing gap between diarrheal and non-diarrheal disease deaths appears to be driven by a slight rise in control disease death rates. We speculate that this slight increase may be related to Mexico's 1989-1990 measles epidemic. Mexico experienced a significant rise in measles attack rates as part of a broader regional pandemic in 1989-1990 (Katz et al. 2004). While we do not include measles mortality in either of our control disease sets, it is still possible that measles may account for the 1989-1990 uptick in these diseases given its association with respiratory diseases, congenital conditions, and skin infections (Orenstein, Perry and Halsey 2004).
} 
neonates (1-12 months), and children ages 1-4), we test for differential trend breaks in diarrheal disease mortality rates in 1991 (when PAL was implemented) relative to two sets of control diseases which should not be directly affected by PAL. ${ }^{17}$ One includes acute upper and lower respiratory infections, including viral bronchitis and pneumonia. We choose these diseases because they were the second-leading cause of child mortality in Mexico prior to $\mathrm{PAL}^{18}$ and because they share several common risk factors with diarrheal diseases (respiratory infections are spread through oral droplets and diarrheal diseases are spread by fecal-oral contamination). Particularly helpful for identification is the fact that respiratory diseases are more sensitive to water quantity (which affords opportunities for preventive handwashing and thus breaking the droplet contamination cycle), while diarrheal diseases are more sensitive to water quality, which is the focus of PAL (Ahuja et al. 2010) - poor drinking water quality is not a direct risk factor for respiratory infections (Fischer Walker et al. 2013b).

Nonetheless, if diarrheal diseases weaken immune systems, raising the likelihood of contracting respiratory infections (Ashraf et al. 2017; Ashraf et al. 2013; Fischer Walker et al. 2013a; Sedgwick and MacNutt 1910), then using respiratory diseases - or infectious diseases in general - as control diseases may underestimate changes in mortality rates associated with PAL. For this reason, we also estimate models using a control group of diseases that are less likely to co-vary with diarrhea (i.e., are biomedically more 'distant'). ${ }^{19}$ These are perinatal causes (low birth weight, birth trauma,

\footnotetext{
${ }^{17}$ A similar strategy was employed by Jayachandran, Lleras-Muney and Smith (2010) in their work on antibiotic therapy in the United States. Closer to our study, Galiani et al. (2005) use non-diarrheal causes of mortality as a falsification test in their study of water service privatization in Argentina.

${ }^{18}$ ICD-9 codes 460-466 and 480-487, respectively.

${ }^{19}$ Co-dependence between diarrheal diseases and these more bio-medically distant controls is also possible if, for example, falling diarrheal disease mortality raises the returns to health behaviors and investments
} 
congenital infections) and congenital anomalies, for all of which poor water quality is not a direct risk factor (Embrey et al. 2004; Pruss-Ustun et al. 2008). ${ }^{20}$

We focus our analysis on municipality-year diarrheal mortality rates in a window around program implementation, 1985-1995 (Appendix Table 2 shows that our substantive results are robust to expanding our study period). We begin by estimating event study specifications of the general form:

$$
\begin{aligned}
& \text { (1) } M_{d j t}=\alpha_{d}+\sum_{t=1985}^{1995} \alpha_{t}(\mathbf{1}(\text { Diarrhead }) \times \mathbf{1}(\text { Year }=t))+ \\
& \sum_{t=1985}^{1995} \mu_{t}(\mathbf{1}(\text { Year }=t))+\lambda_{j}+e_{d j t}
\end{aligned}
$$

Here, $M_{d j t}$ represents the inverse hyperbolic sine transformation of the mortality rate for disease class $d$ in municipality (or state) $j$ and year $t .^{21} \mathbf{1}$ (Diarrhea) is a dummy variable denoting whether or not the cause of death is diarrheal disease (sensitive to water quality, and hence the program intervention) versus a control disease group (not sensitive to water quality); Year is a dummy variable denoting observations in year $t$; and $\lambda_{j}$ represent municipality fixed effects. The parameters of interest are captured by the vector $\alpha_{t}$, which yield the average differential percentage change in the diarrheal disease mortality rate vs. the control disease mortality rate in year $t$ relative to the baseline year (in this

more generally, which would potentially reduce the risk of all of the control diseases (Dow, Philipson and Sala-i-Martin 1999). However, again, this would imply that our estimates are conservative.

${ }^{20}$ ICD-9 codes are as follows: congenital anomalies (ICD9 codes 740-759); perinatal causes (low birth weight, birth trauma, congenital infections, neonatal jaundice, etc: ICD9 codes 764-779).

${ }^{21}$ Formally, the inverse hyperbolic sine transform of some variable, $\mathrm{y}$, is $\ln \left(y+\sqrt{\left(y^{2}+1\right)}\right)$. Estimates obtained using this transformation can be interpreted in the same manner as those obtained using a natural logarithm transformation of the dependent variable, with the advantage of being defined at zero (Burbridge, Magee and Robb 1988). 
specification, 1985). We estimate this equation for overall under-5 mortality rates as well as for disaggregated age intervals (neonates 0-1 months, infants 1-12 months, and children 1-4 years old). ${ }^{22}$ To relax the assumption that the error terms are independent and identically distributed (i.i.d.) within municipalities over time, we consistently cluster the standard-errors at the municipality level (Bertrand, Duflo and Mullainathan 2004).

Then, to estimate average program effects of PAL during the study period (accounting for any disease-specific pre-trends), we use parametric specifications of the following form:

(2) $M_{d j t}=\beta_{0}+\beta_{1}\left(\mathbf{1}\left(\right.\right.$ Diarrhea $\left._{d}\right) \times \mathbf{1}\left(\right.$ Post $\left._{t}\right) \times$ Year $\left.\left._{t}\right)\right)+\beta_{2}\left(\mathbf{1}\left(\right.\right.$ Diarrhea $_{d} \times \mathbf{1}\left(\right.$ Post $\left.\left._{t}\right)\right)+\beta_{3}$

$$
\left(\mathbf{1}(\text { Diarrhead }) \times \text { Year }_{t}\right)+\beta_{4} \mathbf{1}\left(\text { Diarrhea }_{d}\right)+\sum_{t=1985}^{1995} \mu_{t}(\mathbf{1}(\text { Year }=t))+\lambda_{j}+e_{d j t}
$$

Here, $\mathbf{1}($ Post $)$ is a dummy variable for post-PAL years (1991 and later), and all other variables are defined as before. The parameters of interest are $\beta_{1}$ and $\beta_{2}$, which measure trend and level breaks starting in 1991 for diarrheal disease mortality rates relative to control disease mortality rates. The trend and level breaks are net of pre-existing trends in diarrheal disease mortality rates relative to control diseases (captured by $\beta 3$ ); mortality trend breaks and intercept shifts common to all diseases (flexibly absorbed by year fixed effects); and time invariant differences between diarrheal and control disease mortality rates (captured by $\beta_{4}$ ).

\footnotetext{
${ }^{22}$ This model effectively restricts pre-trends and breaks to be identical across each of the component control diseases which we sum together in forming our broader control disease groups. Thus, we additionally estimated versions of this model (as well as the more parametric formulations below), allowing for each of the component control diseases to have their own pre-trends, level, and trend breaks. This did not have any substantive impact on the findings.
} 
As we note in Section 2.1, other less intensive prevention and treatment measures were also introduced around 1991. These components, which were substantially smaller in scope than chlorination, included legal restrictions on wastewater irrigation, hygiene campaigns, some provision of Oral Rehydration Therapy (ORT), and general disease surveillance (CONAGUA 1994; Sepulveda et al. 2006). We would therefore expect estimates in equations (1) and (2) to largely reflect benefits of chlorinated water. However, to isolate the role of chlorination further, we also estimate the following tripledifference specification:

(3) $M_{d j t}=\gamma_{0}+\gamma_{1}\left(\mathbf{1}\left(\right.\right.$ Diarrhea $\left._{d}\right) \times \mathbf{1}\left(\right.$ Small $\left._{d}\right) \times \mathbf{1}\left(\right.$ Post $\left.\left._{t}\right)\right)+$

$$
\begin{aligned}
& \gamma_{2}\left(\mathbf{1}\left(\text { Diarrhea }_{d}\right) \times \mathbf{1}\left(\text { Small }_{d}\right) \times \mathbf{1}\left(\text { Post }_{t}\right) \times \text { Year }_{t}\right)+\sum_{3}^{4} \gamma_{i}(2 \text { Triple Interactions })+ \\
& \sum_{5}^{9} \gamma_{i}(5 \text { Double Interactions })+ \\
& \sum_{10}^{11} \gamma_{i}(2 \text { Linear Terms })+\sum_{t=1985}^{1995} \mu_{t}(\mathbf{1}(\text { Year }=t))+\lambda_{j}+e_{d j t}
\end{aligned}
$$

where $\mathbf{1}\left(\right.$ Small $\left._{d}\right)$ is a dummy variable denoting municipalities encompassing or contained within 'cities' with a population less than 500,000 (as enumerated in the 1990 population census), ${ }^{23}$ and all other variables are defined as before. ${ }^{24}$ The key parameters of interest are $\gamma_{1}$ and $\gamma_{2}$, which capture level and trend breaks in diarrheal disease mortality rates

\footnotetext{
${ }^{23}$ An individual's town of residence in the 1990 census was divided into population sizes of 1-2,499, 2,500-14,999, 15,000-99,999, 100,000-499,999, and 500,000 and above. We calculated the fraction of individuals living in towns of 500,000 or more in each municipality. Any municipality that had a non-zero fraction living in such towns was coded as a large area, and the small area dummy is simply the inverse. Of note, $52 \%$ of the enumerated 1990 census population lived in larger areas, which is similar to the percentage of individuals with access to chlorinated water pre-PAL (55\%, see Figure 2).

${ }^{24}$ The additional triple interactions terms (with subscripts omitted) are $\mathbf{1}$ (Diarrhea) $\times \mathbf{1}($ Small) $\times$ Year and $\mathbf{1}($ Small $) \times \mathbf{1}($ Post $) \times$ Year. The additional double interactions are $\mathbf{1}($ Diarrhea $) \times \mathbf{1}($ Small; $\mathbf{1}($ Diarrhea $) \times$ Year; $\mathbf{1}($ Diarrhea $) \times \mathbf{1}($ Post $) ; \mathbf{1}($ Small $) \times$ Year; , and $\mathbf{1}($ Small $) \times \mathbf{1}($ Post $)$. The single terms are $\mathbf{1}($ Diarrhea $)$ and $\mathbf{1}($ Small). $\mathbf{1}($ Year $)$, and $\mathbf{1}($ Post $) \times$ Year are subsumed by year fixed effects.
} 
relative to control disease mortality rates in small- and medium-size municipalities relative to large cities. ${ }^{25}$ Importantly, because chlorination explicitly targeted small- and medium-sized cities, these estimates are more likely to distinguish the effects of chlorination from any potential effects of other more minor PAL components (not differentially targeted by city size).$^{26}$

We also conduct several additional robustness tests. First, we introduce state-year fixed effects into our specification to flexibly control for any time-variant state-level interventions or processes that may bias our results. Second, we estimate our models using death counts rather than mortality rates. Third, we repeat our estimation using a longer time window (1979-1997).

\subsection{Results}

Figure 4 plots coefficient estimates obtained by estimating Equation (1) for under-5, neonatal (0-1 months), post-neonatal (1-12 months), and child mortality rates (ages 1-4 years) by event year. Consistent with the unadjusted graphs (Figure 3), Figure 4 shows some undulation in diarrheal disease mortality rates relative to the control diseases beginning in 1985 (with the implementation of Mexico's ORT program) - and then a discrete, markedly more rapid decline with the implementation of PAL in 1991, continuing throughout post-implementation years. The presence of modest pre-existing trends, particularly in the case of the respiratory disease controls, highlights the importance of conditioning on disease-specific mortality rate trends and motivates the parameterization of Equation (2).

\footnotetext{
${ }^{25}$ Note that these models control for the full set of disease-municipality size specific pre-existing trends. ${ }^{26}$ In addition, using large cities as controls may also allow us to net out the potential influence of other smaller programs such as PANAZA, which targeted large cities.
} 
Table 2 then reports estimates from Equation (2) by age group. In each age interval, we find statistically significant level and trend breaks in diarrheal disease mortality relative to both sets of control diseases, and these breaks coincide with the introduction of PAL. Specifically, across all models, the estimate for "1(Diarrhea) $\times$ Year" (third row) shows that diarrhea mortality was declining before PAL, and the coefficient on " $1($ Diarrhea $) \times \mathbf{1}($ Post $) \times$ Year" (second row $)$ shows a near doubling of this rate after 1991.

Overall, Table 2 shows a sharp divergence in mortality rate trends between diarrheal diseases and control diseases that began in 1991 following the rapid implementation of PAL. For under-5 mortality rates, specifications using the respiratory controls (Panel A, first column) imply a 58\% reduction in diarrheal disease mortality rates by 1995 . The corresponding reduction using non-infectious childhood diseases as controls (Panel B, first column) is $54 \% .^{27}$ These estimates suggest that over 28,000 deaths were averted among children under age 5 between 1991 and 1995 as a result of PAL. Estimates for neonatal, post-neonatal, and 1-4 mortality rates imply similar declines (columns 2-4, Table 2). ${ }^{28}$

Table 3 reports estimates from Equation (3), exploiting an additional difference between the targeted small- and medium-size municipalities relative to larger cities. The first two rows show triple-difference estimates of level and trend breaks $\left(\gamma_{1}\right.$ and $\gamma_{2}$,

\footnotetext{
${ }^{27}$ To calculate this, we multiplied the coefficient on the trend break, $\mathbf{1}$ (Diarrhea) $\times \mathbf{1}($ Post $) \times$ Year, by 4 (as 1995 is four years after the start of PAL) and added this to the coefficient denoting the level break $(\mathbf{1}($ Diarrhea $) \times \mathbf{1}($ Post $))$.

${ }^{28}$ Using non-infectious childhood disease controls, the estimates for imply 0-1 month olds imply $41 \%$ decline, a 51\% decline for 1-12 month olds, and a 34\% decline for 1-4 year olds (Panel A, second-fourth columns, respectively). Using respiratory disease controls, the respective declines for these ages groups was 53\%, 32\%, and 15\% (Panel B, second-fourth columns). We note that it is not surprising that we find large declines for neonates (0-1 month olds), for whom infectious diarrheal diseases are in fact a major cause of death (Liu et al. 2012).
} 
respectively) associated with PAL. These estimates imply a $37 \%$ and $48 \%$ reduction in diarrheal mortality rates among children under age 5 in specifications using respiratory and non-respiratory controls, respectively. These estimates are substantively similar (and statistically equivalent) to the double-difference estimates in Table 2, confirming our $a$ priori understanding that other peripheral components of PAL were not important contributors to the decline in diarrheal disease death rates among children. ${ }^{29}$

\subsection{Extensions and Robustness}

The substantive results in Table 2 are robust the inclusion of state-year fixed effects, which absorb any time-varying state-level policies (Appendix Table 1); modelling death counts instead of death rates (using a negative binomial model - see Appendix Table 2); and using a longer study window (Appendix Table 3). ${ }^{30}$ Finally, we also examine if areas that experienced larger declines in diarrheal disease mortality rates also experienced larger increases (or declines) in migration, which may bias our estimates, but we find no evidence of differential migration (see Appendix Table 4 and associated notes for further details).

\section{Under What Circumstances is Municipal Water Disinfection Effective?}

The previous section demonstrates large average treatment effects of PAL. Given mixed experiences with water system chlorination/disinfection in many developing countries, which contrasts with the more systematically positive historical experience of

\footnotetext{
${ }^{29}$ The $95 \% \mathrm{CI}$ of the implied effect in the triple difference specification using respiratory infections as a control disease (8-59\%) overlap with those from the double difference specification (40-76\%).

${ }^{30}$ Models using the longer-time series employ death counts, given restrictions on data availability on live births in prior years. The estimates (Appendix Table 3) suggest larger reductions (63\% and 74\% using nonrespiratory and respiratory controls, respectively), likely reflecting the greater difficulty in tightly controlling for pre-trends in the extended time series.
} 
wealthy countries, we next investigate the circumstances under which chlorination can be most effective. We focus on heterogeneity by coverage of municipal water pipe infrastructure, which delivers drinking water to households (and, importantly, chlorinated drinking water under PAL). In general, we would expect to find a positive relationship between pipe network coverage and PAL program effects. However, we find null effects, and we subsequently consider the attenuating role of water system age, positing that older water systems may have been more degraded (and hence less effective in providing clean water). We also examine potential complementarities between PAL chlorination efforts and sanitation infrastructure coverage.

\subsection{Empirical Strategy}

To examine heterogeneous program effects, we first estimate municipalityspecific program effects $\left(D I D_{j}\right)$. To do so, we subtract the difference in diarrheal diseases mortality rates before and after PAL from the same difference in non-infectious childhood control disease mortality rates, accounting for pre-PAL trends in both disease groups. ${ }^{31}$

We then relate these to municipality-level infrastructure - specifically, piped water coverage and sewage infrastructure coverage - using data from the 1990 population census. We begin by estimating regressions of the form:

\footnotetext{
${ }^{31}$ Specifically, we first compute the inverse hyperbolic sine transformation of mortality rates and then compute the pre-trend between 1985 and 1991. We then subtract the predicted values from the postintervention (transformed) mortality rates for each municipality-disease group. We use the non-infectious disease controls given that diarrheal diseases may influence the risk of contracting respiratory infections (see Section 4). We then subtract the pre-intervention means from the de-trended post-intervention mean. Note that this is similar to estimating Equation 2 for each municipality $j$ and then subtracting and using estimates of $\beta_{l j}$ and $\beta_{2 j}$ to compute the percent change in diarrheal mortality rates in the pre- and post-PAL periods (after removing changes in control disease mortality and disease-specific pre-trends). Our results are similar in magnitude (and statistically indistinguishable) even when we account for differences in municipality-disease pre-PAL trends.
} 
where DID is the municipality specific program effect; Piped Water Coverage and Sewage Coverage represents the fraction of households in the 1990 census reporting having a piped water and sewage connection, respectively; and System age is a proxy for the age of the water pipe infrastructure. $\boldsymbol{X}_{\mathrm{j}}$ denotes a vector of municipality specific characteristics (percentage of adults completing secondary schooling, percent indigenous population, and the natural logarithm of average household earnings). We control for these variables to account for possible unmeasured confounders that may jointly influence municipality-specific treatment effects and water and sanitation infrastructure variables. We also assess the sensitivity of our findings to the inclusion of baseline diarrheal disease mortality rates and state-year fixed effects to further account for differences in the disease environment and time-varying state-level policies. ${ }^{32} \mathrm{We}$ estimate specifications using both the full sample and a restricted sample of small- and medium-sized cities (to focus more precisely on areas in which chlorination was introduced).

Equation (4) models the differential effect of chlorination under PAL according to pre-intervention measures of infrastructure. The coefficient estimates can be interpreted

\footnotetext{
${ }^{32}$ Another potential confounder could be political targeting and capacity. For example, the relationship between municipality governance and national policymakers could influence the allocation of transfers and infrastructure development, a phenomenon that has been well-studied in Mexico (Diaz-Cayeros, Estevez and Magaloni 2016). However, Fried and Venkataramani (2016) find no relationship between PAL treatment effects and the pre-PAL municipality governor's political party.
} 
as interactions between PAL and each pre-intervention attribute. An advantage of this approach is that it allows us to examine several interactions simultaneously.

\subsection{Results}

Table 4 reports estimates from Equation (4), both for the full sample and a restricted sample of municipalities with fewer than 500,000 people (which were targeted by PAL). Overall, we find no meaningful relationship between piped water coverage and mortality decline under PAL: the estimates are small and not statistically different from zero. These - and the other estimates described below - are also insensitive to controlling for baseline diarrheal mortality and state fixed effects (Appendix Table 5).

These results may help to explain the discordance between the historical experiences of wealthy countries and those of contemporary developing countries. One possible explanation for the insignificant relationship between piped water coverage and PAL program effect size is that more extensive municipal water systems are older (Office of Economic Cooperation and Development (OECD) 2006; Oswald Spring 2011; Vasquez et al. 2009). Water system age is correlated with the degree of infrastructure degradation in many countries (Larsen et al. 2016; Lee and Schwab 2005; Moe and Rheingans 2006). Consequently, age-related pipe breaks, intermittent water pressure, and resulting recontamination from the surrounding soil may have undermined the full potential health benefits of the PAL (Ercumen, Gruber and Colford 2014; Kumpel and Nelson 2013; Mazari-Hiriart et al. 2005). A substantial literature on Mexico suggests that older municipal water systems are more prone to infrastructure failure and fecal 
contamination (Adler 2015; Lee and Schwab 2005; Mazari-Hiriart et al. 2005; World

Bank 1994). ${ }^{33}$

Because systematic data on water system age, direct measures of degradation, and water pressure (including pressure fluctuations) are not generally available for any country in the world, ${ }^{34}$ including Mexico, this hypothesis is difficult to test directly. To do so, we construct a proxy measure for water system age by calculating the ratio of piped water coverage in the 1960 census to coverage in the 1990 census. Assuming that pre-existing piped water systems were not updated, which is reasonable in the Mexican context (Secretaria de Medio Ambiente y Recursos Naturales 2013), higher ratios imply older water systems. Consistent with this view, Figure 5 shows that this measure of preexisting piped water coverage was positively associated with pipe breaks per kilometer in 2005 in a sample of 16 municipal systems (the most complete data on pipe break density available). ${ }^{35}$

We then assess the relationship between our measure of water system age and piped water coverage in 1990. Figure 6 shows that areas with older water systems did in fact have greater piped water coverage in 1990. Figure 7 then plots the non-parametric relationship between our measure of water system age and municipality-specific PAL

\footnotetext{
${ }^{33}$ For example, a recent government report estimates that 30-50\% of drinking water nationwide may be lost due to pipe age, poor pressure control, and degraded materials (Secretaria de Medio Ambiente y Recursos Naturales 2013). This illustrates how infrastructure-driven deficits in the completeness of disinfection and increases in recontamination risk are widespread.

${ }^{34}$ The best available database for worldwide municipal water system characteristics is maintained by the International Benchmarking Network for Water and Sanitation Utilities (IB-NET, http://www.ib-net.org/). This database includes information on total water system output and usage, infrastructure quality (including pipe breaks), and tariffs for a number of local water systems. We searched this database for information on Mexican utilities. However, data were only available for a small number of utilities and only for 2005 and onwards. Moreover, these utilities were predominantly in major cities, where PAL was less active. We use these data in some suggestive analyses (see below), but their incompleteness precludes more definitive investigation.

${ }^{35}$ The correlation coefficient between the two variables is $0.41, \mathrm{p}=0.11$.
} 
program effects. In general, municipalities with older water systems experience smaller declines in mortality under PAL, suggesting a potentially important role for water system age (and degradation) in limiting the benefits of water system chlorination.

Columns 3 and 4 of Table 4 show that this relationship persists in multivariate parametric regression models. ${ }^{36}$ The estimates from column 4 imply that municipalities with the oldest water infrastructure (by our proxy measure) experienced smaller PAL program effects. Moving from the newest to oldest ventile of water pipe age in our sample is associated with a 32 percentage point reduction in the PAL treatment effect. Thus, the role of water system age and accompanying degradation may be substantial in limiting the potential of water chlorination interventions.

Complementarity with Sanitation Infrastructure. Table 4 shows a positive relationship between sanitation coverage at the municipal level and mortality decline under PAL. This suggests complementarity between water disinfection and sanitation efforts, a pattern consistent with recent work on Massachusetts during the nineteenth century (Alsan and Goldin Forthcoming) and quasi-experimental findings from contemporary India (Duflo et al. 2015). Using the estimates in the fourth column of Table 4 , an interventile increase in municipal sewage coverage (from $0 \%$ to $75 \%$ of the population) was associated with a 57 percentage point greater decline in diarrheal disease mortality rates under PAL. These results suggest that inadequate sanitation could also substantially limit the benefits water system disinfection in developing countries.

Heterogeneity and Comparisons with Historical Experience: Finally, we use estimates from Table 4 (column 4) to predict treatment effects for counterfactual

\footnotetext{
36 The sample sizes for these regressions are smaller due to the small sampling frame (1.5\%) in the 1960 IPUMS census micro data.
} 
scenarios with varying levels of infrastructure. Specifically, we predict post-intervention declines in diarrheal disease mortality using a range of feasible values for piped water system age and sewage coverage. Figure 8 shows these results across the distribution of our proxy for water pipe age. The blue point estimates and shaded regions depict predictions for water systems in the bottom ventile of observed sewage coverage, while water systems at the top ventile are shown in red.

Importantly, our estimates suggest that Mexican municipalities in the highest ventile of both water pipe age and sewage coverage would have experienced an $80 \%$ decline in diarrheal mortality, averting nearly 31,000 child deaths between 1991-1995. This large decline generally comparable to historical experiences in developed countries - suggesting that infrastructure quality may play a central role in explaining why contemporary disinfection efforts in many developing countries are less successful. (By contrast, our results strikingly also suggest that mortality would not have declined at all municipalities in the lowest ventile of water pipe age and sewage coverage).

\section{Behavioral Responses}

In this section, we study the behavioral responses of households to public investments in municipal water quality. As with poor quality infrastructure, compensating behavioral responses may also attenuate the ultimate benefits of municipal water disinfection (and may have been less important historically, prior to widespread knowledge about bacteriology, when wealthy countries first began disinfecting their water) (Bennett 2012; Dow et al. 1999; Keskin et al. 2015).

\subsection{Empirical Strategy}


Because the ENIGH surveys are nationally representative repeated cross-sections that do not sample the same municipalities over time, we study behavioral responses to PAL at the state-level using the following approach:

$$
\begin{aligned}
& Y_{i j t}=\alpha_{0}+\alpha_{1}\left(\mathbf{1}\left(\text { Post }_{t}\right) \times \text { Base_Diarrhea } j\right)+\alpha_{2}\left(\mathbf{1}\left(\text { Post }_{t}\right) \times \text { Base_Control }_{j}\right) \\
& +\boldsymbol{\alpha} \boldsymbol{X}_{i j t}+\lambda_{i}+\theta_{t}+u_{i j t}
\end{aligned}
$$

where $Y_{i j t}$ is the inverse hyperbolic sine transform of total spending on mineral/purified water and soaps/detergents in household $i$, state $j$, and time $t$; Base_Diarrhead is the average under-5 diarrheal disease mortality rate during the four years prior to PAL; $\mathbf{1}\left(\right.$ Post $\left._{t}\right)$ is a binary indicator $=1$ if the survey year was after PAL was initiated (1991 or thereafter); $\boldsymbol{X}_{i j t}$ is a vector of individual and household characteristics (age of household head and the natural logarithm of household income); and $\lambda_{j}$ and $\theta_{t}$ represent state and year fixed effects (respectively). ${ }^{37}$ Negative estimates of $\alpha_{1}$, the key parameter of interest, would reflect compensatory behavioral responses under PAL. Although we do not have direct measures of hygienic behaviors, our assumption, which is supported by

\footnotetext{
${ }^{37}$ This strategy was introduced by Card (1992) and has recently been used in a number of health-related studies (Bhalotra and Venkataramani 2015b; Bleakley 2007, 2010; Cutler et al. 2010). Identification in this "continuous differences-in-differences" model comes from exploiting the sudden introduction of PAL (captured by Post) combined with variation across states in potential benefits from the program. The premise is that program impacts are larger in regions in which the disease burden is larger prior to introduction of the program, or that the program generates convergence in disease rates. We formally test for convergence in diarrheal mortality graphically and by estimating the following:

$$
M_{i j t}=\alpha_{0}+\alpha_{l}\left(\mathbf{1}\left(\text { Post }_{t}\right) \times \text { Base_Diarrhea } a_{j}+\lambda_{j}+\theta_{t}+u_{i j t}\right.
$$

where $M_{i j t}=$ the municipality-specific diarrhea mortality rate and the other variables are as defined for Model 5 in the main text. An estimate of $\alpha_{1}>0$ is consistent with convergence. This model assesses absolute convergence. Estimating the same model using the logarithm of the mortality rate provides evidence of relative convergence. We find evidence of convergence in child diarrhea mortality (Appendix Figure 2 and Appendix Table 6).
} 
the epidemiology literature (Kamm et al. 2014; Pickering et al. 2010), is that household spending on disinfectants and clean water from alternative sources is a reasonable marker for sanitary behaviors that reduce diarrheal disease risk.

\subsection{Results}

Table 5 reports estimates from Equation (4). In our full sample, we find small, negative, and imprecise estimates of compensatory behavioral responses (estimates of $\alpha_{1}$ shown in column 1). However, among households living in small and medium cities, the areas targeted by PAL, we find a statistically significant negative relationship with household spending on soap, disinfectants, and bottled water (column 2). Specifically, moving from the worst performing quartile of states in the pre-program distribution of diarrhea mortality rates to the top quartile is associated with a $6.7 \%$ decrease in spending on these goods. ${ }^{38}$ We find no statistically significant behavioral responses among households in large cities which had disinfected water prior to PAL (column 3). ${ }^{39}$

These results provide evidence of significant compensatory behavioral responses to PAL (or "crowd-out"). However, although we are unable to distinguish the independent health decrement associated with them from the direct health benefits of PAL, the fact that we nonetheless find large reductions in diarrhea mortality rates under PAL implies that the degree of crowd-out is far from complete.

\footnotetext{
${ }^{38}$ This effect appears to be driven primarily by soap and detergent purchases, with null findings for mineral and purified water purchases. Appendix Table 7 provides further details.

${ }^{39}$ Further, we find that impacts within these small and medium sized towns and cities were only seen for households with both sanitation and piped water access and not for households with only piped access or neither amenity (few households have sanitation access without piped water access). While these estimates (available upon request) are imprecisely estimated, the pattern of coefficients is consistent with the complementarity between disinfection and sanitation noted in Section 5.
} 


\section{Cost Effectiveness}

We have shown that PAL was associated with large reductions in diarrheal disease mortality, but a natural question is whether this was worth the expense relative to alternative uses of these public funds. To calculate the cost per child death averted and the cost per life year saved, we use the estimates from Table 2 for total under-5 mortality rates (using non-respiratory controls). We focus on the period 1991-1995 given that we know the total cost of the program over this time frame: PAL cost approximately U.S. \$1 billion over this period (or $\$ 1.86$ billion in 2015 dollars) ${ }^{40}$ Of course, the health benefits of PAL presumably continued accruing after 1995. Depending on the costs of ongoing maintenance and operation of chlorination facilities, our results may understate the costeffectiveness of the program. ${ }^{41}$

For each year between 1991 and 1995, we calculate the differential reduction in diarrheal disease mortality rates using the estimates for the level shift (Diarrhea $\times$ Post) and trend break (Diarrhea $\times$ Post $\times$ Year). We multiply these estimated rate changes by the average number of live births in small and medium-sized towns in each year prior to PAL to recover the implied number of averted deaths. We then sum the implied number of averted deaths across years 1991-1995. Overall, the implied cost per death averted under PAL was $\$ 65,981$ (Table 6).

Assuming that individuals surviving childhood would have lived to the age of 60 (conservative given that the average life expectancy at the time of the policy was 71

\footnotetext{
${ }^{40}$ Personal communication with Dr. Jaime Sepulveda, Mexico's Vice-Minister of Health from 1991 to 1994.

${ }^{41}$ Another reason our estimates may be conservative is that we do not account for additional program benefits beyond life years saved. For example, other work demonstrates robust short run benefits of water infrastructure on short-run financial transactions (Ashraf et al, 2017) and time allocations and long-run benefits of infant exposure to PAL on cognitive outcomes and schooling for girls (Bhalotra and Venkataramani 2015a).
} 
years), the cost per life year saved was \$1,100. Estimates using the upper 95\% CI of our estimates imply a cost per life year saved of $\$ 1,577$ (or $\$ 900$ using the lower 95\% CI). We also use the estimates from Table 4 to assess cost-effectiveness in settings for the counterfactual scenario in which all municipalities have good quality infrastructure (i.e, equivalent to the top ventile of the pipe age proxy and sewage coverage observed in our sample). The $80 \%$ decline in diarrheal disease mortality predicted for this scenario, implying nearly 34,000 averted child deaths between 1991-1995, would cost $\$ 900$ per life year saved.

\section{Discussion and Conclusion}

Despite the widespread adoption of effective water disinfection technology worldwide over the last century, poor water quality remains a key challenge in low- and middle-income countries. The sources of this problem likely extend beyond weak governance and regulation. In particular, existing urban water and sanitation infrastructure in developing countries are old and degraded - a challenge that is now being exacerbated by rapid urbanization (United Nations Development Programme (UNDP) 2006). Identifying underlying technological factors that alter the returns to disinfection is thus critical to maximize the potential of large-scale water quality initiatives in the future.

Mexico's Programa Agua Limpia provides an unusual contemporary opportunity to study the potential of state-funded municipal water disinfection on a national scale. On average, we find that the program successfully reduced childhood diarrheal disease mortality rates by $50 \%$. Moreover, we find that PAL was highly cost-effective, with a 
cost per life year saved of $\$ 1,100$. However, while some areas experienced large reductions, others enjoyed little health benefit. We also find evidence of compensatory reductions in household hygiene investments, but the degree of crowd-out is far from complete.

To identify additional investments that may be necessary for municipal water disinfection to realize its full potential, we also examine the conditions under which PAL was effective. Studying municipal-level variation across the entire country, we find evidence suggesting that water system age, and associated degradation, may play an important role (because recontamination is more likely in degraded systems with intermittent water pressure, for example). We also find evidence of meaningful complementarities between water disinfection and pre-existing sewage infrastructure. Maximizing the returns to large-scale water quality interventions may require concurrent investments in repairing degraded water pipes and in sewage infrastructure. Overall, we emphasize the complexity of contemporary urban water and sanitation challenges in developing countries - and the need for more research on how to improve the safety of municipal drinking water. 


\section{References}

Adler, D. 2015. "The war for Mexico's water." in Foreign Policy.

Ahuja, A., M. Kremer, and A.P. Zwane. 2010. "Providing safe water: Evidence from randomized evaluations." Annual Review of Resource Economics 2:237-256.

Alsan, M.and C. Goldin. Forthcoming. "Watersheds in infant mortality: The role of effective water and sewerage infrastructure, 1880 to 1915." Journal of Political Economy.

Arnold, B., C. Null, S.P. Luby, L. Unicomb, C. Stewart, K.G. Dewey, T. Ahmed, S. Ashraf, G. Christensen, T. Clasen, H.N. Dentz, L.C.H. Fernald, R. Haque, A.E. Hubbard, P. Kariger, E. Leontsini, A. Lin, S.M. Njenga, P.A. J, P.K. Ram, F. Tofail, P.K. Winch, and J.M. Colford. 2013. "Cluster-randomised controlled trials of individual and combined water, sanitation, hygiene and nutritional interventions in rural Bangladesh and Kenya: the WASH Benefits study design and rationale." BMJ Open 3:e003476

doi:003410.001136/bmjopen-002013-003476.

Arnold, B.F.and J.M. Colford. 2007. "Treating water with chlorine at point-of-use to improve water quality and reduce child diarrhea in developing countries: A systematic review and meta-analysis." American Journal of Tropical Medicine and Hygiene 76(2):354-364.

Ashraf, N., E. Glaeser, A. Holland, and B. Millet Steinberg. 2017. "Water, health and wealth." NBER working Paper No. 23807.

Ashraf, S., M.H. Huque, M. Agboatwalla, and S.P. Luby. 2013. "Effect of recent diarrheal episodes on risk of pneumonia in children under the age of 5 years in Karachi, Pakistan." International Journal of Epidemiology 42(1):194-200.

Bain, R., R. Cronk, J. Wright, H. Yang, T. Slaymaker, and J. Bartram. 2014. "Fecal contamination of drinking-water in low- and middle-income countries: A systematic review and meta-analysis." PLoS Medicine 11(5):e1001644.

doi:1001610.1001371/journal.pmed.1001644.

Barham, T. 2011. "A healthier start: the effect of conditional cash transfers on neonatal and infant mortality in rural Mexico." Journal of Development Economics 94:74-85.

Bennett, D. 2012. "Does clean water make you dirty? Water supply and sanitation in the Philippines." Journal of Human Resources 47(1):146-173. 
Bertrand, M., E. Duflo, and S. Mullainathan. 2004. "How much should we trust differences-in-differences estimates?" Quarterly Journal of Economics 119(1):249-275.

Bhalotra, S.and A.S. Venkataramani. 2015a. "Human capital and infectious disease: Gender differences in investments and outcomes." Mimeo, University of Essex.

—. 2015b. "Shadows of the Captain of the Men of Death: Early life health interventions, human capital, and institutions." Mimeo, University of Essex.

Bhutta, Z.A., J.K. Das, N. Walker, A. Rizvi, H. Campbell, I. Rudan, and R.E. Black. 2013. "Interventions to address deaths from childhood pneumonia and diarrhoea equitably: what works and at what cost?" Lancet 381(9875):1417-1429.

Bleakley, H. 2007. "Disease and Development: Evidence from Hookworm Eradication in the American South." The Quarterly Journal of Economics 122(1):73-117.

—. 2010. "Malaria Eradication in the Americas: A Retrospective Analysis of Childhood Exposure." American Economic Journal: Applied Economics 2:1-45.

Brown, R.R., N. Keath, and T.H. Wong. 2009. "Urban water management in cities: Historical, current, and future regimes." Water Science and Technology 59(5):847-855.

Burbridge, J.B., L. Magee, and A.L. Robb. 1988. "Alternative transformations to handle extreme values of the dependent variable." Journal of the American Statistical Association 83(401):123-127.

Cain, L.P.and E.J. Rotella. 2001. "Death and spending: Urban mortality and municipal expenditure on sanitation." Annales de Demographie Historique 1(101):139-154.

Cameron, A.C., J.B. Gelbach, and D. Miller. 2008. "Boostrap-based improvements for inference with clustered errors." Review of Economics and Statistics 90(3):414-427.

Card, D. 1992. "Using regional variation in wages to measure the effects of the federal minimum wage." Industrial and Labor Relations Review 46(1):22-37.

Clasen, T.and L. Haller. 2008. "Water quality interventions to prevent diarrhoea: Cost and cost-effectiveness."

CONAGUA. 1994. "Informe, 1989-1994." Mexico City, Mexico: Comision Nacional Del Agua. 
Crocker, K.and S. Masten. 2002. "Prospects for private water provision in developing countries: Lessons from 19th century America." in Thirsting for Efficiency: The Economics and Politics of Urban Water Reform, edited by M. Shirley. London: Elsevier.

Cutler, D., W. Fung, M. Kremer, M. Singhal, and T. Vogl. 2010. "Early-Life Malaria Exposure and Adult Outcomes: Evidence from Malaria Eradication in India." American Economic Journal: Applied Economics 2:72-94.

Cutler, D., F. Knaul, R. Lozano, O. Mendez, and B. Zurita. 2002. "Financial crisis, health outcomes and ageing: Mexico in the 1980s and 1990s." Journal of Public Economics 84(2):279-303.

Cutler, D.M.and G. Miller. 2005. "The role of public health improvements in health advances: The twentieth-century United States." Demography 42(1):1-22.

—. 2006. "Water, water everywhere: Municipal finance and water supply in American cities." Pp. 153-184 in Corruption and Reform: Lessons from America's Economic History, edited by E. Glaeser and C. Goldin. Chicago: University of Chicago Press.

Diaz-Cayeros, A., F. Estevez, and B. Magaloni. 2016. The Political Logic of Poverty Relief: Electoral Strategies and Social Policy in Mexico. New York: Cambridge University Press.

Diaz-Cayeros, A.and B. Magaloni. 2003. "The politics of public spending - Part II. The Programa Nacional de Solidaridad (PRONASOL) in Mexico." in World Development Report Background Paper. Washington D.C.: World Bank.

Dow, W.H., T.J. Philipson, and X. Sala-i-Martin. 1999. "Longevity complementarities under competing risks." American Economic Review 89(5):1358-1371.

Duflo, E., M. Greenstone, R. Guiteras, and T. Clasen. 2015. "Toilets can work: Short and medium run health impacts of addressing complementarities and externalities in water and sanitation." NBER Working Paper No. 21521.

Dupas, P. 2011. "Health behavior in developing countries." Annual Review of Economics 3:425-449.

Embrey, M., P. Hunter, J. Sellwood, P. Wyn-Jones, S.L. Percival, and R. Chalmers. 2004. Microbiology of Waterborne Diseases. San Diego and London: Elseview.

Ercumen, A., B. Arnold, E. Kumpel, Z. Burt, I. Ray, K. Nelson, and J.M. Colford. 2015. "Upgrading a piped water supply from intermittent to continuous delivery and association 
with waterborne illness: A matched cohort study in urban India." PLoS Medicine 12(10):e1001892. doi: 1001810.1001371/journal.pmed.1001892.

Ercumen, A., J.S. Gruber, and J.M. Colford. 2014. "Water distribution system deficiencies and gastrointestinal illness: A systematic review and meta-analysis." Environmental Health Perspectives 122(7):651-660.

Ferrie, J.P.and W. Troesken. 2008. "Water and Chicago's mortality transition, 18501925." Explorations in Economic History 45:1-16.

Fewtrell, L., R.B. Kaufmann, D. Kay, W. Enanoria, L. Haller, and J.M. Colford. 2005. "Water, sanitation, and hygiene interventions to reduce diarrhoea in less developed countries: a systematic review and meta-analysis." Lancet Infectious Diseases 5(1):42-52.

Fischer Walker, C., J. Perin, J. Katz, J.M. Tielsch, and R.E. Black. 2013a. "Diarrhea as a risk factor for acute lower respiratory tract infections among children in low income settings." Journal of Global Health 3(1):doi: 10.7189/jogh.7103.010402.

Fischer Walker, C., I. Rudan, H. Nair, E. Theodoratou, Z.A. Bhutta, K.L. O'Brien, H. Campbell, and R.E. Black. 2013b. "Global burden of childhood pneumonia and diarrhoea." Lancet 381(9875):1405-1416.

Foster, A., E. Gutierrez, and N. Kumar. 2009. "Voluntary compliance, pollution levels, and infant mortality in Mexico." American Economic Review 99(2):191-197.

Fotso, J.-C., A.C. Ezeh, N.J. Madise, and J. Ciera. 2007. "Progress towards the child mortality millenium development goal in urban sub-Saharan Africa: The dynamics of population growth, immunization, and access to clean water." BMC Public Health 7(218):doi:10.1186/1471-2458-1187-1218.

Frenk, J., J. Sepulveda, O. Gomez-Dantes, and F. Knaul. 2003. "Evidence-based health policy: Three generations of reform in Mexico." The Lancet 362(9396):1667-1671.

Fried, B.J.and A. Venkataramani. 2016. "Does saving lives win votes? Evaluating the electoral consequences of a water disinfection program in Mexico." Mimeo, Brandeis University.

Gadgil, A. 1998. "Drinking water in developing countries." Annual Review of Energy and Environment 23:253-286.

Galiani, S., P. Gertler, and E. Schargrodsky. 2005. "Water for life: The impact of the privatization of water services on child mortality." Journal of Political Economy 113(1):83-120. 
Gonzalez, F.and T. Quast. 2011. "Macroeconomic changes and mortality in Mexico." Empirical Economics 40(2):305-319.

Greenstone, M.and R. Hanna. 2014. "Enviromental regulations, air and water pollution, and infant mortality in India." American Economic Review 104(10):3038-3072.

Gruber, J.S., F. Reygadas, B. Arnold, I. Ray, K. Nelson, and J.M. Colford. 2013. "A stepped wedge, cluster-randomized trial of a household UV-disinfection and safe storage drinking water intervention in rural Baja California Sur, Mexico." American Journal of Tropical Medicine and Hygiene 89(2):238-245.

Gutierrez, R., R. Tapia-Conyer, H. Guiscafre, H. Reyes, H. Martinez, and J. Kumate. 1996. "Impact of oral rehydration and selected public health interventions on reduction of mortality from childhood diarrhoeal diseases in Mexico." Bulletin of the World Health Organization 74(2):189-197.

Hernandez, B., D. Ramirez-Villalobos, M.B. Duarte, A. Corcho, G. Villareal, A. Jimenez, and L.M. Torres. 2012. "Subregistro de defunciones de menores y certificación de nacimiento en una muestra representativa de los 101 municipios con más bajo índice de desarrollo humano en México." Salud Publica de Mexico 54(4):393-400.

Jayachandran, S., A. Lleras-Muney, and K.V. Smith. 2010. "Modern medicine and the twentieth century decline in mortality: Evidence on the impact of sulfa drugs." American Economic Journal: Applied Economics 2(2):118-146.

Jeandron, A., J.M. Saidi, A. Kapama, M. Burhole, F. Birembano, T. Vandevelde, A. Gasparrini, B. Armstrong, S. Cairncross, and J.H.J. Ensink. 2015. "Water supply interruptions and suspected cholera incidence: A time-series regression in the Democratic Republic of the Congo." PLoS Medicine 12(10):e1001893. doi:1001810.1001371/journal.pmed.1001893.

Kamm, K., D. Feikin, G. Bigogo, G. Aol, A. Audi, A. Cohen, M. Shah, J. Yu, R. Breiman, and P.K. Ram. 2014. "Tropical Associations between presence of handwashing stations and soap in the home and diarrhea and respiratory illness in children less than five years old in rural western Kenya and International Health." Tropical Medicine and International Health 19(4):398-406.

Katz, S.L., J.I. Santos, M.A. Nakamura, M.V. Godoy, P. Kuri, C.A. Lucas, and R.T. Conyer. 2004. "Measles in Mexico, 1941-2001: interruption of endemic transmission and lessons learned." Journal of Infectious Diseases 189(Suppl 1):S243-S250.

Keskin, P., G.K. Shastry, and H. Willis. 2015. "Water quality awareness and breastfeeding: evidence of health behavior change in bangladesh." Review of Economics and Statistics Forthcoming. 
Ketzenbaum, L.and J.-L. Rosenthal. 2014. "Income versus sanitation: Mortality decline in Paris, 1880-1914." PSE Working Paper.

Knutsson, D. 2016. "The effect of introducing clean piped water on mortality in Stockholm: 1850-1872." Mimeo, Stockholm University.

Koppaka, R. 2011. "Ten great public health achievements: Worldwide, 2001-2010." Morbidity and Mortality Weekly Report 60(24):814-818.

Kremer, M., J. Leino, E. Miguel, and A.P. Zwane. 2011. "Spring cleaning: Rural water impacts, valuation, and property rights institutions." Quarterly Journal of Economics 126(1):145-205.

Kumpel, E.and K. Nelson. 2013. "Comparing microbial water quality in an intermittent and continuous piped water supply." Water Research 47(14):5176-5188.

Kumpel, E.and K.L. Nelson. 2014. "Mechanisms affecting water quality in an intermittent piped water supply." Environmental Science and Technology 48:2766-2775.

Larsen, T.A., S. Hoffman, C. Luthi, B. Truffer, and M. Maurer. 2016. "Emerging solutions to the water challenges of an urbanizing world." Science 352(6288):928-933.

Lee, E.J.and K.J. Schwab. 2005. "Deficiencies in drinking water distribution systems in developing countries." Journal of Water and Health 3:109-127.

Liu, L., H.L. Johnson, S. Cousens, J. Perin, S. Scott, J.E. Lawn, I. Rudan, H. Campbell, R. Cibulskis, M. Li, C. Mathers, and R.E. Black. 2012. "Global, regional, and national causes of child mortality: An updated systematic analysis for 2010 with time trends since 2000." The Lancet 389(9832):9-15.

Lozano-Ascencio, R. 2008. "Is it possible to improve the death registries in Mexico?" Gaceta Medica de Mexico 144(6):525-533.

Masten, S. 2011. "Public utility ownership in 19th-century America: the "aberrant" case of water." Journal of Law, Economics, and Organization 27(3):604-654.

Mathers, C.D., D. Fat, M. Inoue, C. Rao, and A. Lopez. 2005. "Counting the dead and what they died from: an assessment of global status of cause of death data." Bulletin of the World Health Organization 83:171-177.

Mazari-Hiriart, M., Y. Lopez-Vidal, S. Ponce-de-Leon, J.J. Calva, F. Rojo-Callejas, and G. Castillo-Rojas. 2005. "Longitudinal study of microbial diversity and seasonality in the 
Mexico City metropolitan area water supply system." Applied and Environmental Microbiology 71(9):5129-5137.

McDonald, R.I., K. Weber, J. Padowski, M. Florke, C. Schneider, P.A. Green, T. Gleeson, S. Eckman, B. Lehner, D. Balk, T. Boucher, G. Grill, and M. Montgomery. 2014. "Water on an urban planet: Urbanization and the reach of urban water infrastructure." Global Environmental Change 27:96-105.

Medina, E. 1991. "Epidemia de cólera en Chile; 1991." Revista medica de Chile 119(8):943-956.

Melosi, M. 2000. The Sanitary City: Urban Infrastructure in America from Colonial Times to the Present. Baltimore: Johns Hopkins Press.

Minnesota Population Center. 2015. Integrated Public Use Microdata Series, International: Version 6.4. Minneapolis: University of Minnesota.

Moe, C.L.and R.D. Rheingans. 2006. "Global challenges in water, sanitation and health." Journal of Water and Health 4(S1):41-57.

Mota-Hernandez, F.and L. Velasquez-Jones. 1985. "Aspectos estrategicos para la implementacion de un Programa Nacional para la rehidratacion oral en la diarrea." Boletin Medico del Hospital Infantil de Mexico 42(8):463-465.

Office of Economic Cooperation and Development (OECD). 2006. "Water management policy brief for the Mexican Project." Mexico: Office of Economic Cooperation and Development, Enviromental Directorate,

Ogasawara, K.and T. Inoue. 2015. "Public health improvements and mortality in early twentieth-century Japan." Mimeo, Tokyo Institute of Technology.

Orenstein, W.A., R.T. Perry, and N.A. Halsey. 2004. "The clinical significance of measles: a review." Journal of Infectious Diseases 189(Suppl 1):S4-S16.

Oswald Spring, U. 2011. "Water resources in Mexico: scarcity, degradation, stress, conflicts, management, and policy." edited by H.G. Brauch. Heidelberg: Springer.

Pickering, A.J., A.B. Boehm, M. Mwanjali, and J. Davis. 2010. "Efficacy of waterless hand hygiene compared with handwashing with soap: a field study in Dar es Salaam, Tanzania." American Journal of Tropical Medicine and Hygiene 82(2):270-278.

Preston, S.H.and E. van de Walle. 1978. "Urban French mortality in the Nineteenth Century." Population Studies 32:275-297. 
Pruss-Ustun, A., R. Bos, F. Gore, and J. Bartram. 2008. Safer water, better health: cost, benefits, and sustainability of interventions to protect and promote health. Geneva: World Health Organization.

Quandt, R.E. 1960. "Test of the hypothesis that a linear regression system obeys two separate regimes." Journal of the American Statistical Association 55(290):324-330.

Ries, A.A., D.J. Vugia, L. Beingolea, A.M. Palacios, E. Vasquez, J.G. Wells, N. Garcia Baca, D.L. Swerdlow, M. Pollack, N.H. Bean, L. Seminario, and R.V. Tauxe. 1992. "Cholera in Piura, Peru: A modern urban epidemic." Journal of Infectious Diseases 166(6):1429-1433.

Secretaria de Medio Ambiente y Recursos Naturales. 2013. "Programa Nacional Hidrico, 2014-2018." Tlalpan, Mexico: Secretaria de Medio Ambiente y Recursos Naturales,.

Sedgwick, W.T.and J.S. MacNutt. 1910. "On the Mills-Reincke phenomenon and Hazen's theorem concerning the decrease in mortality from disease other than typhoid fever following the purification of public water-supplies." Journal of Infectious Diseases 7(4):489-564.

Sepulveda, J., F. Bustreo, R. Tapia, J. Rivera, R. Lozano, G. Olaiz, V. Partida, M.D. Garcia, and J.L. Voldespino. 2007. "Improvement of child survival in Mexico: The diagonal approach." Salud Publica de Mexico 49:S110-S125.

Sepulveda, J., J. Valdespino, and L. Garcia-Garcia. 2006. "Cholera in Mexico: The paradoxical benefits of the last pandemic." International Journal of Infectious Diseases 10(1):4-13.

Shaheed, A., J. Orgill, M.A. Montomgery, M.A. Jeuland, and J. Brown. 2014. "Why "improved" water sources are not always safe." Bulletin of the World Health Organization 92:283-289.

The World Bank. 1995. "Project Completion Report, Mexico: Water Supply and Sanitation Sector Project (Loan 3271-ME)." in Environment and Urban Development Division Country Dept II - Latin America and the Caribbean Region: The World Bank.

Tokajian, S.and F. Hashwa. 2003. "Water quality problems associated with intermitted water supply." Water Science and Technology 47(3):229-234.

Tome, P., H. Reyes, C. Pina, L. Rodriguez, and G. Gutierrez. 1997. "Characteristics associated with the under-registration of deaths in the state of Guerreo, Mexico." Salud Publica de Mexico 39(6):523-529. 
Tulchinsky, T.H., E. Burla, M. Clayman, C. Sadik, A. Brown, and S. Goldberger. 2000. "Safety of community drinking-water and outbreaks of waterborne enteric disease: Israel, 1976-97." Bulletin of the World Health Organization 78(12):1466-1473.

Turneaure, F.E.and H.L. Russell. 1901. Public Water-Supplies: Requirements, Resources, and the Construction of Works. New York: John Wiley \& Sons.

UNICEF, WHO, The World Bank, and UN Population Division. 2007. "Levels and Trends of Child Mortality in 2006: Estimates Developed by the Inter-Agency Group for Chold Mortality Estimation." New York.

United Nations Development Programme (UNDP). 2006. "Beyond Scarcity: Power, Poverty, and the Global Water Crisis, Human Development Report 2006." New York.

United Nations Population Division. 2014. "World urbanization prospects: the 2014 revision, highlights (ST/ESA/SER.A/352)." United Nations.

Vasquez, W.F., P. Mozumder, J. Hernandez-Arce, and R.P. Berrens. 2009. "Willingness to pay for safe drinking water: Evidence from Parral, Mexico." Journal of Environmental Management 90(11):3391-3400.

Velazquez, F.R., H. Garcia-Lozano, E. Rodriguez, Y. Cervantes, A. Gomez, M. Melo, L. Anaya, J.C. Ovalle, J. Torres, B.D. De Jesus, C. Alvarez-Lucas, T. Breuer, O. Munoz, and P. Kuri. 2004. "Diarrhea morbidity and mortality in Mexican children: Impact of rotavirus disease." Pediatric Infectious Disease Journal 23(10):S149-S155.

Vos, T., R.M. Barber, B. Bell, A. Bertozzi-Villa, S. Biryukov, I. Bollinger, and et al. 2015. "Global, regional, and national incidence, prevalence, and years lived with disability for 301 acute and chronic diseases and injuries in 188 countries, 1990-2013: A systematic analysis for the Global Burden of Disease Study 2013." The Lancet 386:743800 .

World Bank. 1994. "Staff Appraisal Report, Mexico, Second Water Supply and Sanitation Sector Project." World Bank.

Zwane, A.P.and M. Kremer. 2007. "What works in fighting diarrheal diseases in developing countries? A critical review." World Bank Research Observer 22(1):1-24. 


\section{Figure 1: Pre-Intervention Under-5 Diarrheal Mortality Rates Across Mexican Municipalities (1985-1990 average)}

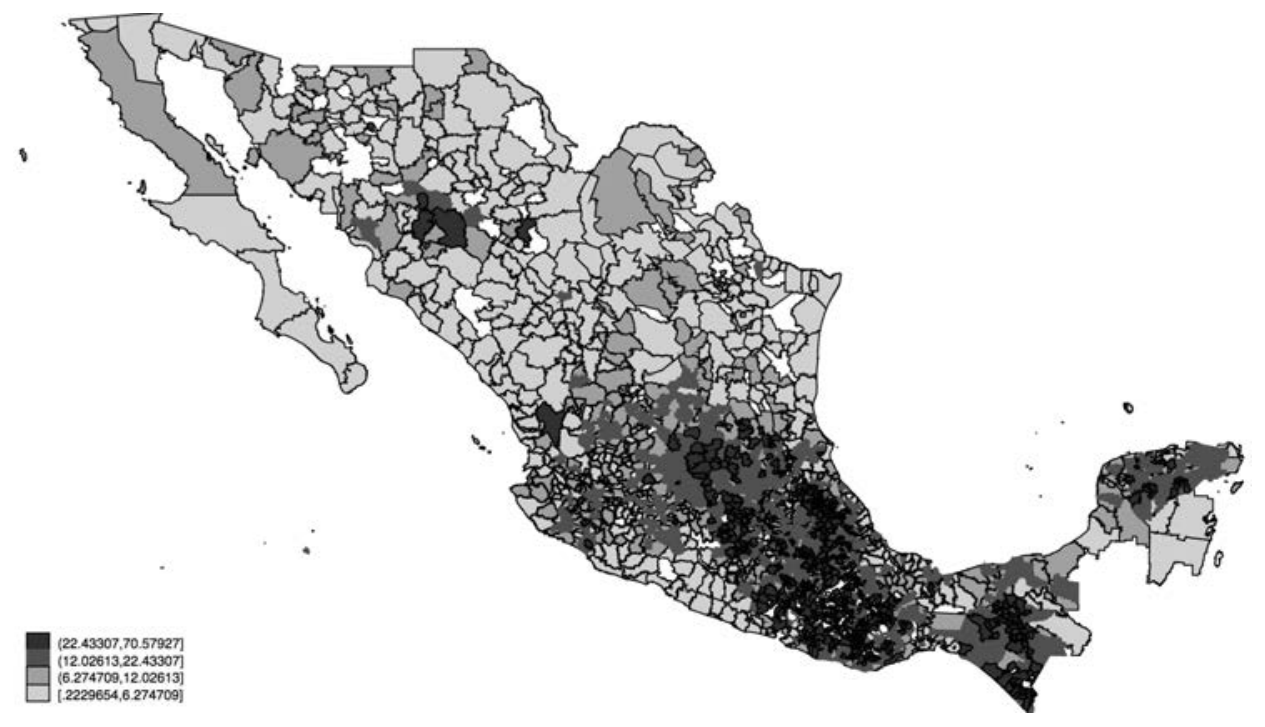

Notes: Map plots average diarrheal mortality rates per 1,000 live births over the period 1985-1990 for children under the age of 5 by municipality. Darker colors reflect higher average preintervention diarrheal mortality rates. Data to construct map were obtained from the Mexico Ministry of Health, Vital Statistics.

\section{Figure 2: Chlorination Coverage under Programa Agua Limpia}

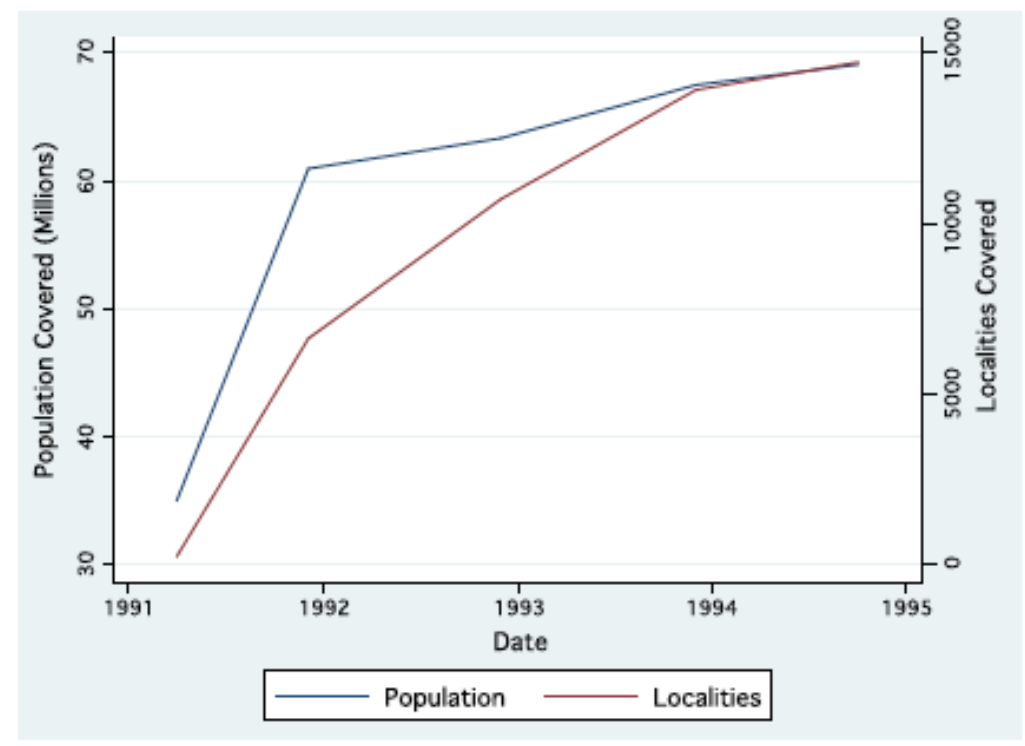

Notes: Figure plots the share of the population (blue) and number of localities (red) covered by chlorinated water between April 1991 and December 1995. The sharp uptick in the population share covered between April 1991 and December 1991 was coincident with the introduction of Programa Agua Limpia (PAL). Data were obtained from CONAGUA (1994). 


\section{Figure 3: National Trends in Under-5 Mortality Rates by Cause}

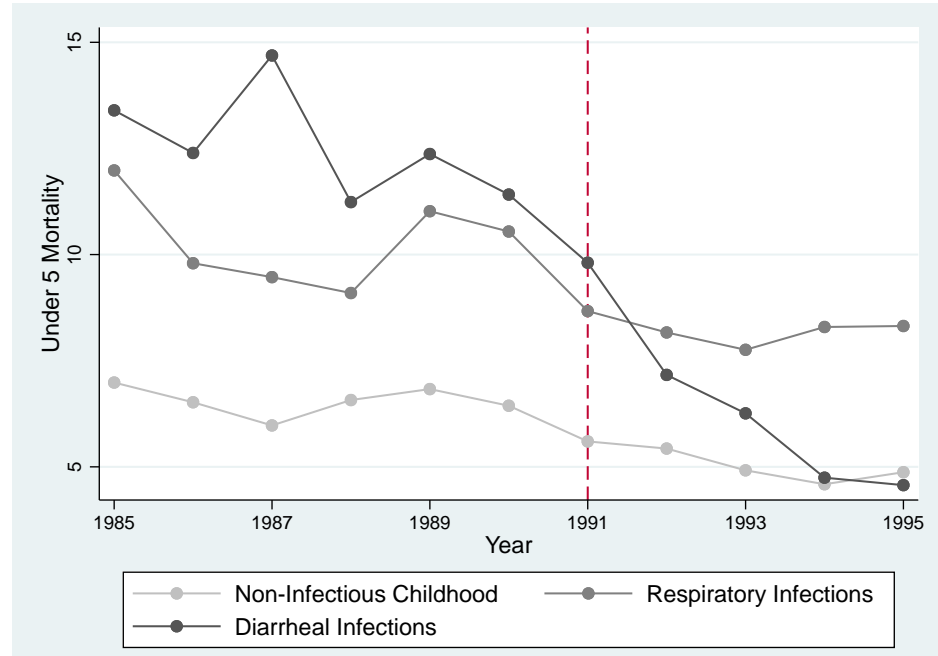

Notes: Figure plots the average trends in mortality rates for diarrheal disease and the two sets of control diseases - respiratory infections and non-infectious childhood diseases - for non-rural municipalities the study period 1985-1995. Visually, we note a trend break in the diarrheal mortality series in 1991, coincident with the start of PAL. This break was confirmed econometrically using the Quandt Likelihood Ratio test $(F=11.16, \mathrm{p}=0.004)$ applied to a longer time series (1979-1997, see Appendix Figure 1; specifically, we assessed for the presence of breaks between 1985-1995). No statistically significant break was found for the control diseases (for non-infectious childhood diseases, the identified break year was $1995(F=0.86, \mathrm{p}=0.37)$ and for respiratory disease, the break year was $1987(F=2.06, \mathrm{p}=0.17)$. Data source: Ministry of Health, Vital Statistics. 


\section{Figure 4: Event Study Coefficient Plots}

A

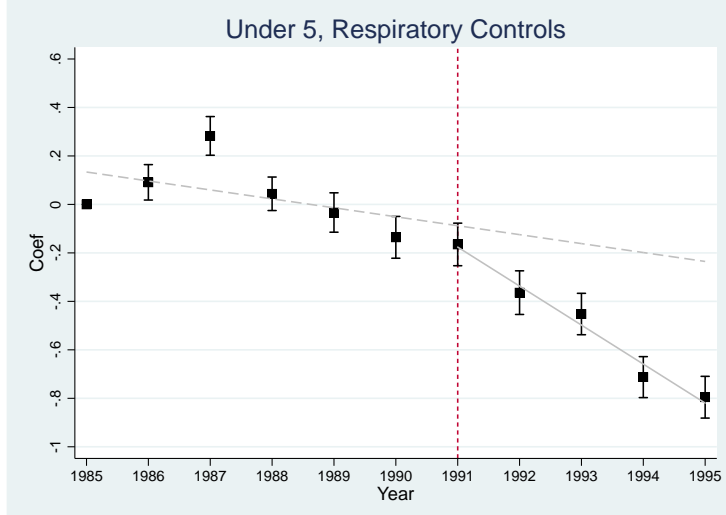

C
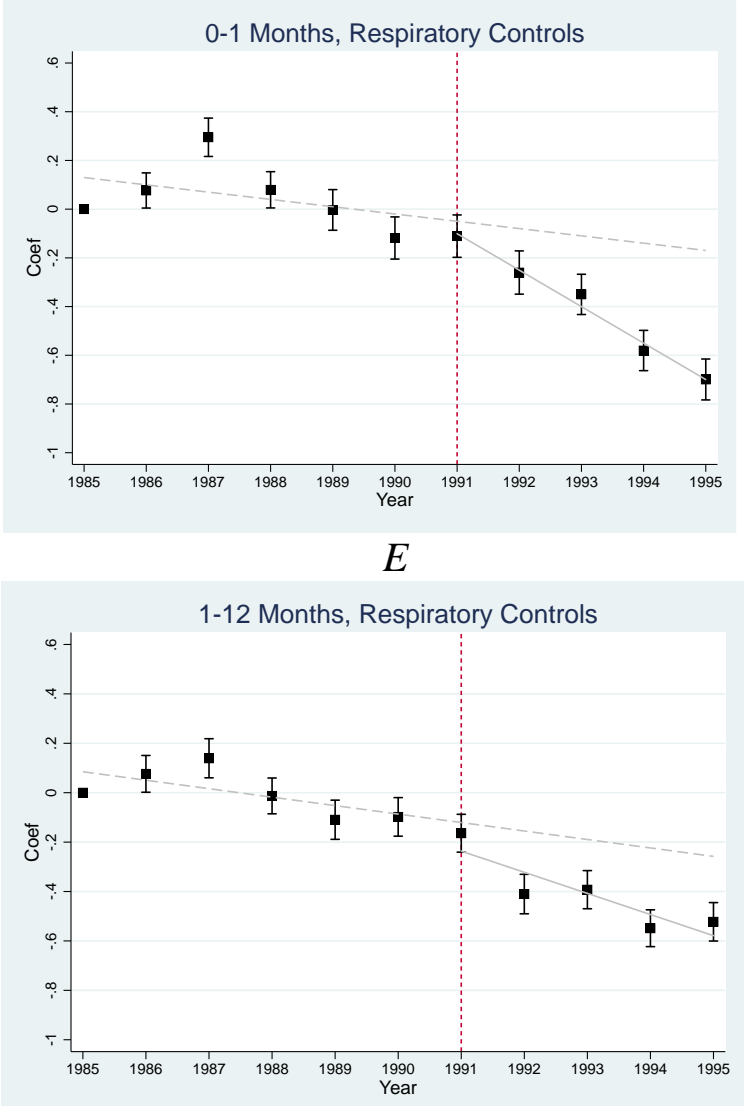

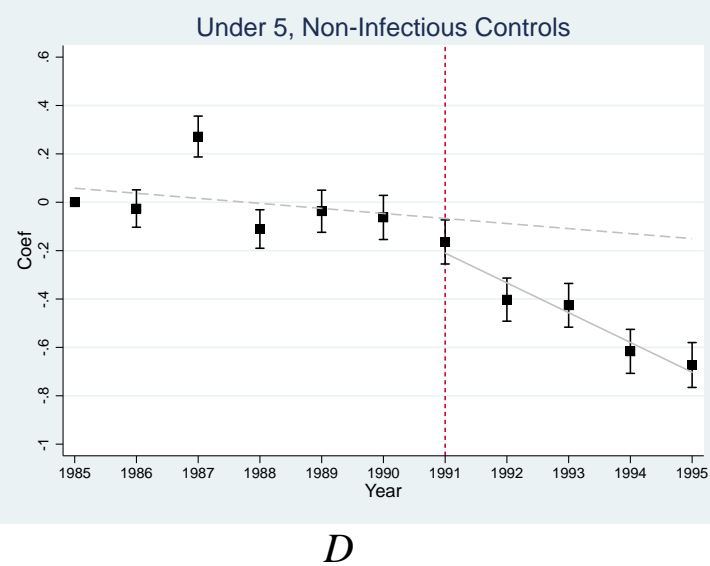

0-1 Months, Non-Infectious Controls

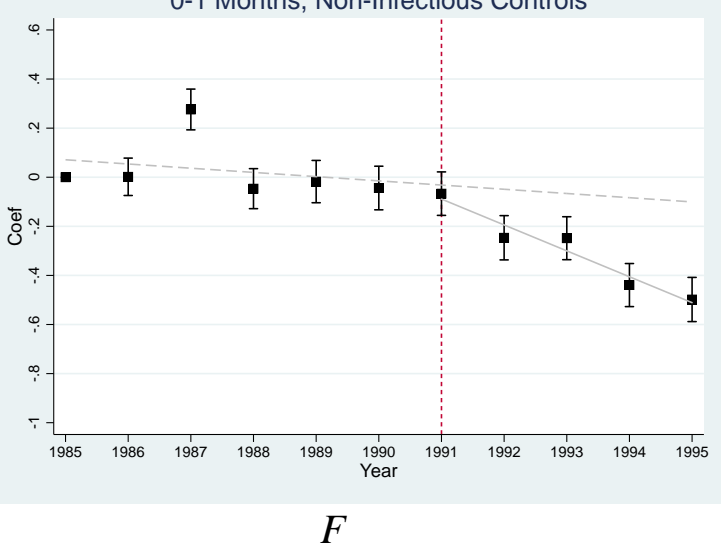

1-12 Months, Non-Infectious Controls

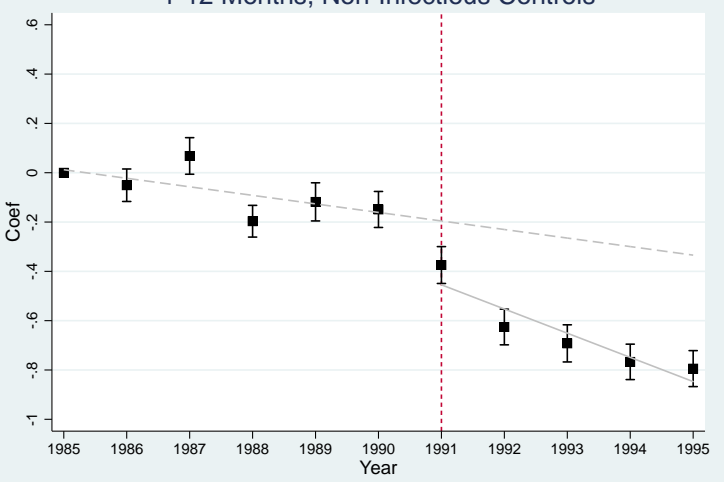




\section{$G$}

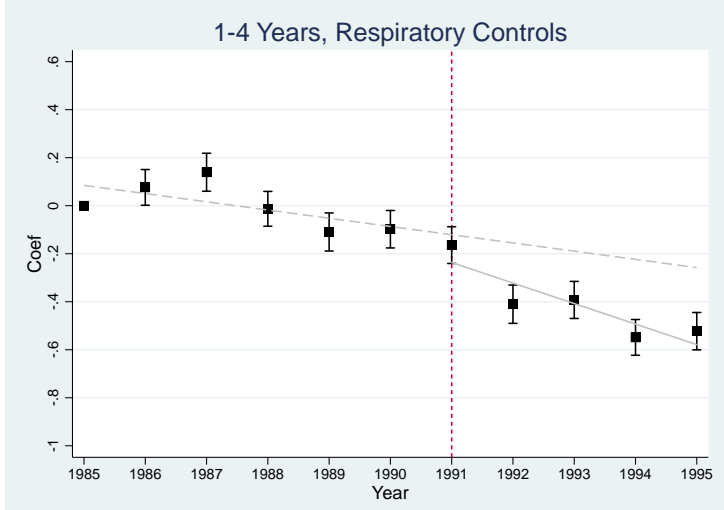

$H$

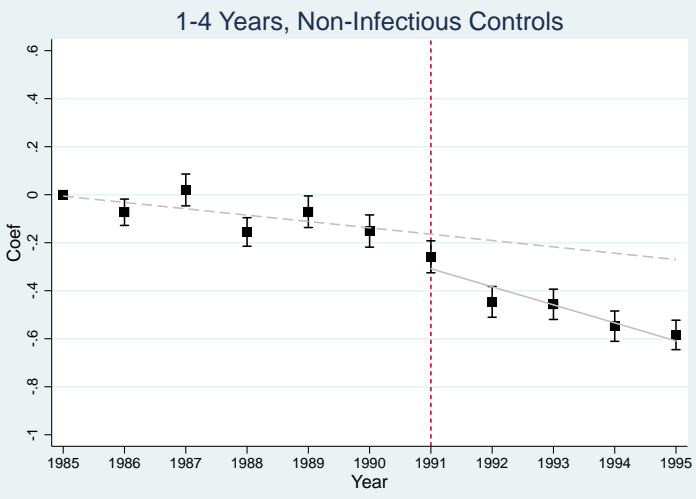

Notes: Panels A-H plot estimates of the Diarrhea $\times$ Year coefficients $\left(\alpha_{t}\right)$ from Equation 1 using either respiratory (left panel) infectious diseases or non-infectious childhood diseases (right panel) as controls. Panels A and B plot estimates for all children under age 5 and the remaining panels examine specific age subgroups (neonatal and post-neonatal refer to 0-1 month-olds and 1-12 month-olds, respectively).

Coefficients are denoted by the dots and the vertical line and whiskers denote the $95 \%$ confidence interval of the estimates. The dashed line is a predicted trend line calculated using pre-1991 coefficients, which we extend across the time series. The solid line is the trend line for the 1991-1995 coefficients. The gap between the two can be interpreted as the PAL treatment effect. 


\section{Figure 5: Relationship Between Water System Age and Pipe Breaks}

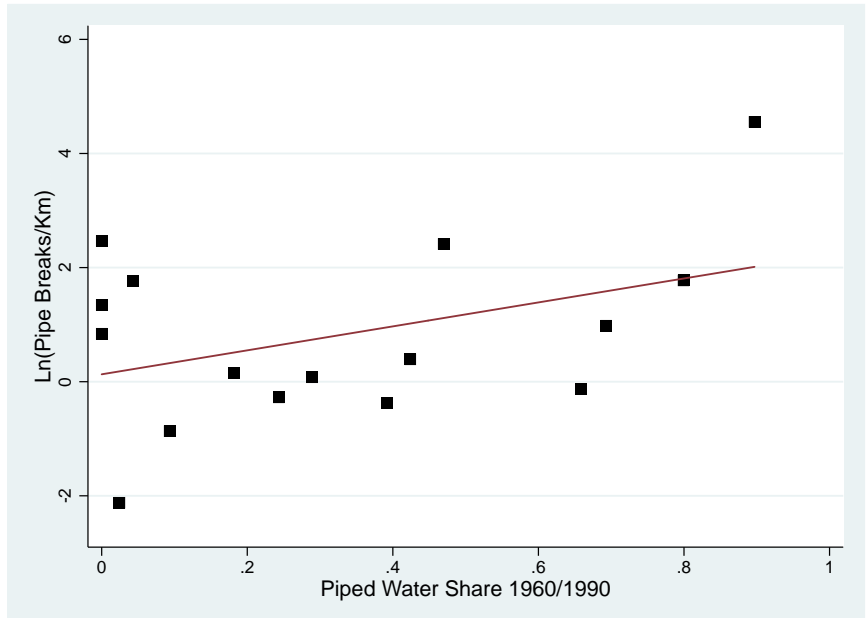

Notes: Scatter plot of logged pipe breaks per kilometer in 16 municipal water systems (distributed across 11 states) in 2005 against the ratio of households with access to piped water in (1960/1990), which we use as a proxy for system age. Data on pipe breaks were obtained from the International Benchmarking Network for Water and Sanitation Utilities (IB-NET, http://www.ib-net.org/). The best-fit line reveals a positive correlation between these variables $(\rho=0.41, \mathrm{p}=0.11)$.

\section{Figure 6: Water System Age and 1990 Population Coverage}

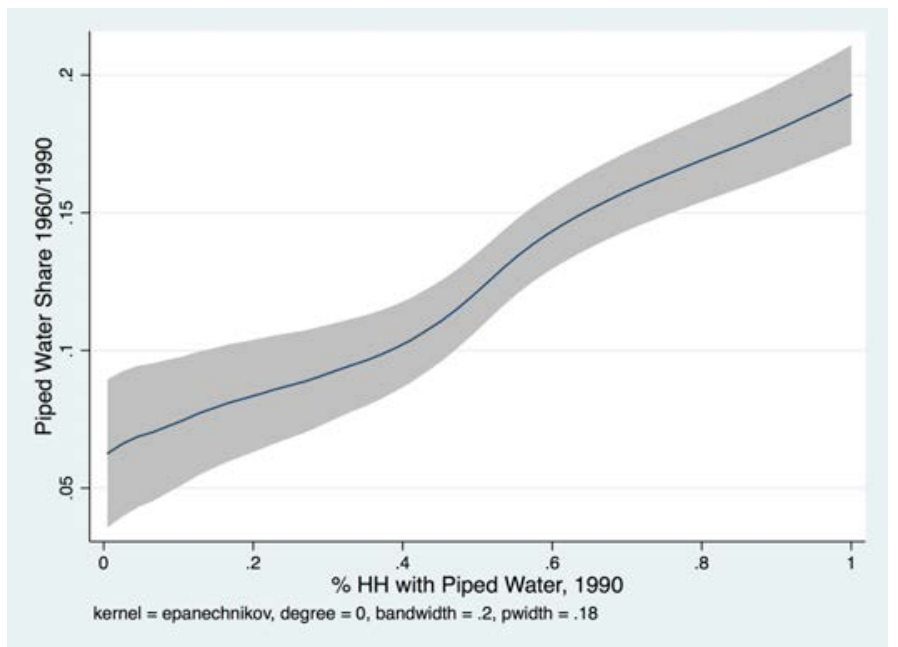

Notes: LOWESS smoothed plots (with 95\% CI) of municipality specific ratios of household piped water coverage between 1960 and 1990 (our proxy for water system age) against coverage in 1990. The positive slope of the plot suggests that systems with higher population coverage pre-PAL may also have been older and, therefore, dilapidated. Figure 5 directly makes the case for the latter point, linking the 1960/1990 access ratio to pipe breaks in 2005. 
Figure 7: PAL Program Effects and Water System Age

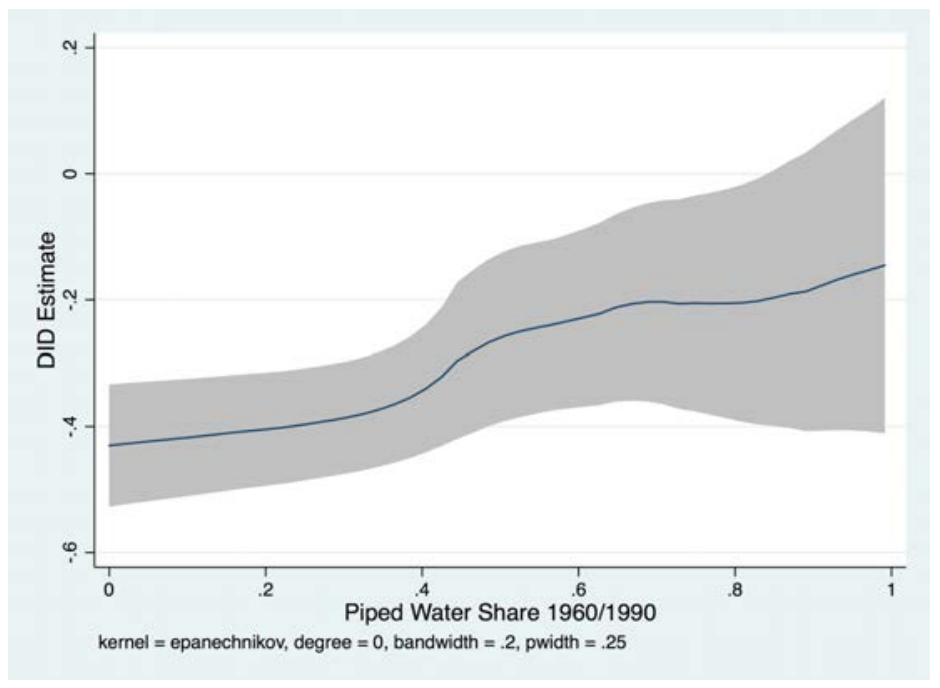

Notes: LOWESS smoothed plots (with 95\% CI) of municipality specific differences-indifferences estimates and the ratio of piped water coverage between 1960 and 1990 (our proxy for water system age).

Figure 8: Infrastructure Quality and Heterogeneous Effects of PAL

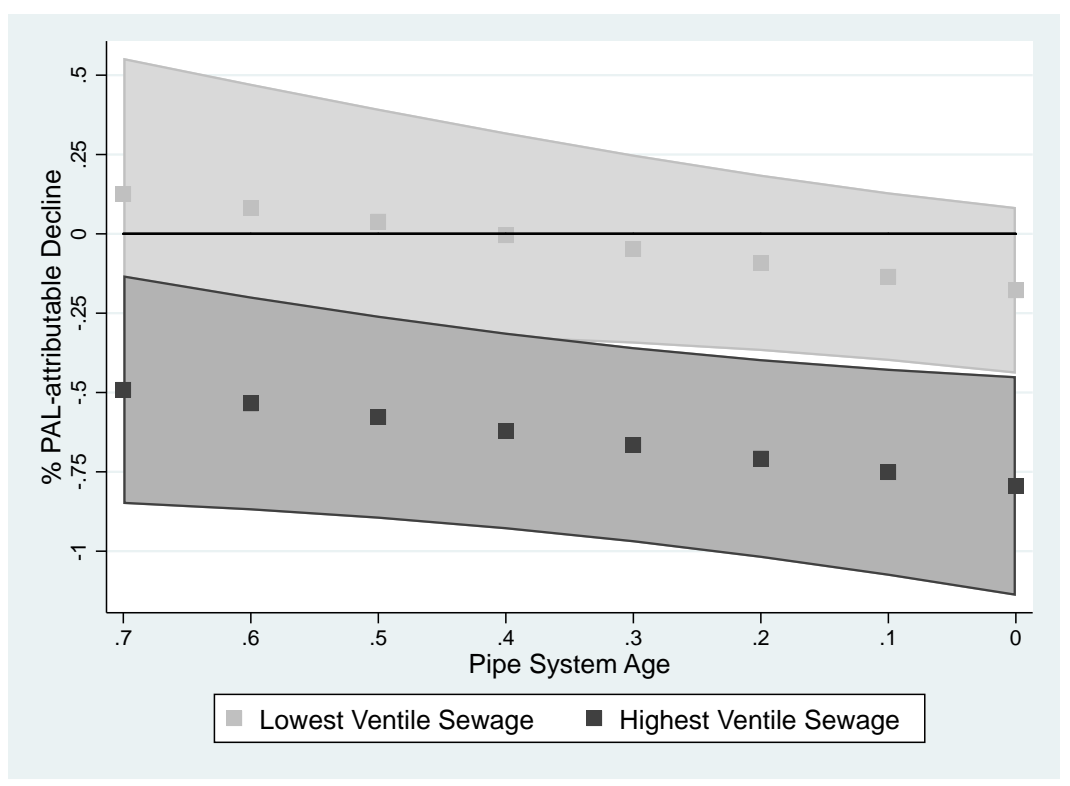

Notes: Predicted PAL treatment effects and confidence intervals for different infrastructure regimes based on regressions in column (4) of Table 4. Predictions calculated over the $90^{\text {th }}-10^{\text {th }}$ percentile interval of pipe water system age (based on the piped water share proxy variable, $\mathrm{X}$ axis) for both the bottom (light grey) and top (dark grey) deciles of sewage coverage (6\% and $73 \%$, respectively) in the sample. The bottom right of the graph reflects predicted estimates for municipalities in the highest decile of both sewage coverage and water system age. 
Table 1: Descriptive Statistics

\begin{tabular}{|c|c|c|c|c|c|c|c|c|c|}
\hline & \multicolumn{3}{|c|}{ Pre-PAL } & \multicolumn{3}{|c|}{ Post-PAL } & \multicolumn{3}{|c|}{ Full Sample } \\
\hline & Mean & S.D. & $\mathbf{N}$ & Mean & S.D. & $\mathbf{N}$ & Mean & S.D. & $\mathbf{N}$ \\
\hline \multicolumn{10}{|l|}{ Vital Statistics Data (1985-1995, Municipality Level) } \\
\hline Under-5 Diarrheal Mortality Rate & 10.8 & 10.4 & 8,424 & 5.2 & 5.9 & 7,020 & 8.2 & 9.7 & 15,444 \\
\hline \multicolumn{10}{|l|}{ Control Diseases } \\
\hline Under-5 Non-Infectious Childhood Disease Mortality Rate & 8.3 & 7.7 & 8,358 & 7.7 & 6.4 & 6,965 & 8.0 & 7.8 & 15,323 \\
\hline Under-5 Respiratory Mortality Rate & 10.4 & 9.3 & 8,376 & 8.8 & 6.6 & 6,980 & 9.6 & 8.2 & 15,356 \\
\hline \multicolumn{10}{|l|}{ Municipality Characteristics, 1990 Census } \\
\hline$\%$ HH with Access to Piped Water & 0.80 & 0.18 & 1,314 & & & & & & \\
\hline$\% \mathrm{HH}$ with Access to Sewage & 0.60 & 0.26 & 1,314 & & & & & & \\
\hline$\%$ Adults Completing Secondary Schooling & 5.3 & 1.38 & 1,314 & & & & & & \\
\hline Average Per Capita Earnings (Pesos, 1000) & 43628 & 16471 & 1,314 & & & & & & \\
\hline Population & $5,012,389$ & $8,497,095$ & 1,314 & & & & & & \\
\hline \multicolumn{10}{|l|}{ ENIGH Data $(1989,1992,1994$ waves; Individual Level) } \\
\hline Total Expenditure on Sanitation Goods (Peso) & 1428 & 1113.15 & 11,176 & 810.11 & 1360.57 & 22,558 & 1015.022 & 1316.469 & 33,734 \\
\hline Household Head Age & 45.05 & 15.43 & 11,176 & 44.58 & 15.39 & 22,558 & 44.74 & 15.41 & 33,734 \\
\hline Household Head Gender ( $=1$ if Male) & 0.86 & 0.35 & 11,176 & 0.86 & 0.34 & 22,558 & 0.86 & 0.34 & 33,734 \\
\hline Household Head Less then Primary $(=1)$ & 0.49 & 0.50 & 11,176 & 0.51 & 0.50 & 22,558 & 0.50 & 0.50 & 33,734 \\
\hline Primary Complete $(=1)$ & 0.25 & 0.43 & 11,176 & 0.24 & 0.43 & 22,558 & 0.24 & 0.43 & 33,734 \\
\hline Secondary Complete & 0.12 & 0.33 & 11,176 & 0.13 & 0.34 & 22,558 & 0.13 & 0.33 & 33,734 \\
\hline Diploma or Above & 0.15 & 0.35 & 11,176 & 0.13 & 0.34 & 22,558 & 0.13 & 0.34 & 33,734 \\
\hline Household with Piped Water $(=1)$ & 0.60 & 0.50 & 11,176 & 0.53 & 0.50 & 22,558 & 0.55 & 0.50 & 33,734 \\
\hline
\end{tabular}

Notes: Descriptive statistics for non-rural municipalities, divided by pre-PAL (data from prior to 1991) and post-PAL (data from 1991 or thereafter). Vital Statistics data reflect weighted under-5 deaths per 1000 live births, with the sample size denoting municipality-year observations. Diarrheal diseases denote infectious diarrhea (ICD9 codes 001-009). Non-infectious childhood diseases comprise of the sum of death rates from congenital anomalies (ICD9 codes 740759), perinatal causes (low birth weight, birth trauma, congenital infections, neonatal jaundice, etc: ICD9 codes 764-779). Respiratory diseases consist of the sum of death rates from acute upper and lower respiratory infections (ICD9 codes 60-466, 480-487 respectively). Death statistics are weighted by the mean number of live births in each municipality between 1985-1991. Municipality characteristics from 1990 (taken as a pre-PAL baseline) were computed using the IPUMS 1990 Census 10\% micro data (Minnesota Population Center, 2015), aggregated (using appropriate weights) to the municipality level. The piped water variable reflects the percentage of households in a municipality with access to piped water either at their home or via a public tap. The sewage variable reflects the percentage of households with on premises access to a sewage system. The earnings variable is the mean total annual household earned income in 1990 pesos (the large numbers reflect significant currency devaluation over the 1980s-early 1990s). Finally, the ENIGH data are taken from the 1989, 1992 , and 1994 waves of the Encuestas Nacional de Ingresos y Gastos de los Hogares, a national household income and consumption survey. The sanitation goods variable reflects the total amount spent in the prior month on soaps, detergents, and bottled or purified water. We combine these into a single class to reduce the number of zeros, since we used logged expenditures in our empirical models. 
Table 2: Differences-in-Differences Models: Diarrheal Relative to Control Disease Trend Breaks Pre-Post PAL

\begin{tabular}{|c|c|c|c|c|c|c|c|c|}
\hline & \multicolumn{4}{|c|}{ Panel A - Respiratory Infections Control } & \multicolumn{4}{|c|}{ Panel B - Non-Infectious Childhood Diseases Control } \\
\hline & Under-5 Years & 0-1 Months & 1-12 Months & 1-4 Years & Under-5 Years & 0-1 Months & 1-12 Months & 1-4 Years \\
\hline 1(Diarrhea)*1(Post) & $\begin{array}{l}-0.0883 \\
(0.0374)\end{array}$ & $\begin{array}{l}-0.0509 \\
(0.0384)\end{array}$ & $\begin{array}{c}-0.116 \\
(0.0332)\end{array}$ & $\begin{array}{c}0.0123 \\
(0.0312)\end{array}$ & $\begin{array}{c}-0.143 \\
(0.0368)\end{array}$ & $\begin{array}{l}-0.0570 \\
(0.0367)\end{array}$ & $\begin{array}{c}-0.259 \\
(0.0279)\end{array}$ & $\begin{array}{c}-0.144 \\
(0.0240)\end{array}$ \\
\hline $1($ Diarrhea $) * 1($ Post $) *$ Year & $\begin{array}{c}-0.124 \\
(0.0137)\end{array}$ & $\begin{array}{c}-0.12 \\
(0.0134)\end{array}$ & $\begin{array}{l}-0.0513 \\
(0.0111)\end{array}$ & $\begin{array}{l}-0.0412 \\
(0.0101)\end{array}$ & $\begin{array}{c}-0.102 \\
(0.0132)\end{array}$ & $\begin{array}{l}-0.0884 \\
(0.0130)\end{array}$ & $\begin{array}{l}-0.0635 \\
(0.0103)\end{array}$ & $\begin{array}{c}-0.0487 \\
(0.00864)\end{array}$ \\
\hline 1(Diarrhea)*Year & $\begin{array}{c}-0.0369 \\
(0.00780)\end{array}$ & $\begin{array}{c}-0.0299 \\
(0.00786)\end{array}$ & $\begin{array}{c}-0.0343 \\
(0.00684)\end{array}$ & $\begin{array}{c}-0.0331 \\
(0.00677)\end{array}$ & $\begin{array}{c}-0.0208 \\
(0.00793)\end{array}$ & $\begin{array}{c}-0.0172 \\
(0.00774)\end{array}$ & $\begin{array}{c}-0.0346 \\
(0.00664)\end{array}$ & $\begin{array}{c}-0.0264 \\
(0.00598)\end{array}$ \\
\hline 1(Diarrhea) & $\begin{array}{c}0.0382 \\
(0.0356)\end{array}$ & $\begin{array}{c}-0.131 \\
(0.0361)\end{array}$ & $\begin{array}{c}0.195 \\
(0.0300)\end{array}$ & $\begin{array}{c}0.202 \\
(0.0278)\end{array}$ & $\begin{array}{c}0.546 \\
(0.0354)\end{array}$ & $\begin{array}{c}0.0150 \\
(0.0356)\end{array}$ & $\begin{array}{c}1.219 \\
(0.0296)\end{array}$ & $\begin{array}{c}0.734 \\
(0.0270)\end{array}$ \\
\hline $\begin{array}{l}\mathrm{N} \\
\mathrm{R} \text {-squared }\end{array}$ & $\begin{array}{c}30,800 \\
0.42\end{array}$ & $\begin{array}{c}30,800 \\
0.37\end{array}$ & $\begin{array}{c}30,800 \\
0.47\end{array}$ & $\begin{array}{c}30,800 \\
0.37\end{array}$ & $\begin{array}{c}30,833 \\
0.42\end{array}$ & $\begin{array}{c}30,833 \\
0.39\end{array}$ & $\begin{array}{c}30,833 \\
0.49\end{array}$ & $\begin{array}{c}30,833 \\
0.41\end{array}$ \\
\hline \% Decline by 1995 Due to $P A L$ & $-58 \%$ & $-53 \%$ & $-32 \%$ & $-15 \%$ & $-55 \%$ & $-41 \%$ & $-51 \%$ & $-34 \%$ \\
\hline
\end{tabular}

Notes: Estimates of Equation 2 in the main text. Robust standard errors, correcting for clustering at the municipality level, are provided in parenthesis. All models include municipality and year fixed. Each column represents a separate regression, with the panel header denoting the control diseases used and the column header the specific age group over which the inverse hyperbolic sine transformation of mortality was calculated for the dependent variable. 1(Diarrhea) $=1$ denotes diarrheal mortality rates, while $\mathbf{1}($ Diarrhea $)=0$ denotes the control disease (see Table 1 notes for details). Post $=1$ if the year of observation is 1991 or thereafter. The level $(\mathbf{1}($ Diarrhea $) \times \mathbf{1}($ Post $))$ and trend $(\mathbf{1}($ Diarrhea $) \times \mathbf{1}($ Post $) \times$ Year $)$ break estimates are in bold. The coefficients on $\mathbf{1}($ Diarrhea $) \times Y e a r$ pick up pre-existing trends in the diarrheal disease series relative to the control diseases. Pre-trends and level and trend breaks for the control diseases are picked up the year fixed effects

The sample size reflects the number of municipality-years. The final row, \% Decline by 1995 Due to PAL is calculated by adding the coefficient on the level break to four times that on the trend break (since 1995 is 4 years after PAL). The year variable is rescaled such that $1991=0$ and increments above and below are denoted by positive and negative integers. 


\section{Table 3: Triple Difference Models: Diarrheal Disease Mortality $\times$ Post-intervention $\times$ Small (Targeted) vs Large Municipality}

\begin{tabular}{lcc}
\hline & $\begin{array}{c}\text { Respiratory } \\
\text { Control }\end{array}$ & $\begin{array}{c}\text { Non-Infectious } \\
\text { Childhood } \\
\text { Diseases Control }\end{array}$ \\
\hline $\mathbf{1}($ Diarrhea)*1(Post)*1(Small) & 0.0659 & 0.0524 \\
& $(0.0593)$ & $(0.0639)$ \\
$\mathbf{1}$ (Diarrhea)*1(Post)*1(Small)*Year & -0.109 & -0.139 \\
& $(0.0207)$ & $(0.0221)$ \\
N & 30,800 & 30,767 \\
R-squared & 0.43 & 0.44 \\
\% Decline by 1995 Due to PAL & $-37 \%$ & $-50 \%$ \\
\hline
\end{tabular}

Notes: Estimates of Equation 3 from the main text. Robust standard errors, correcting for clustering at the municipality level, are in parenthesis. All models include municipality and year fixed effects. Each column is a separate regression and reflects estimates of Equation 3 in the main text. Specifically, we include a third difference - municipality size - in these models. Size is captured by a binary indicator denoting municipalities with populations $\angle 500,000=1$. Those larger already generally chlorinated water systems in place. While only 97 municipalities in the sample are contained in large urban areas $>1,000,000$ people (Small = 0), they accounted for $52 \%$ of the population in 1990 - almost exactly the proportion of the population who had access to disinfected water prior to PAL (Figure 2). 00 The final row, \% Decline by 1995 Due to PAL is calculated by adding the coefficient on the level break to four times that on the trend break (since 1995 is 4 years after PAL). The year variable is rescaled such that $1991=0$ and increments above and below are denoted by positive and negative integers. 
Table 4: Determinants of Municipality-Specific Program Effects

\begin{tabular}{lcccc}
\hline & Full Sample & $\begin{array}{c}\text { Excluding } \\
\text { Large Cities }\end{array}$ & Full Sample & $\begin{array}{c}\text { Excluding } \\
\text { Large Cities }\end{array}$ \\
\hline \% HH with Access to Piped Water & -0.561 & -0.606 & -0.693 & -0.761 \\
& $(0.326)$ & $(0.341)$ & $(0.336)$ & $(0.353)$ \\
\% HH with Access to Sewage System & -0.136 & -0.114 & -0.0686 & -0.0431 \\
& $(0.305)$ & $(0.318)$ & $(0.310)$ & $(0.323)$ \\
Piped Water Coverage Ratio (1960/1990) & & & & \\
& & & 0.359 & 0.434 \\
N & & & & $(0.227)$ \\
R-squared & 1,041 & 968 & 1,041 & $(0.252)$ \\
\hline
\end{tabular}

Notes: Estimates of Equation 4 in the main text. All models are at the municipality level and are weighted by municipality population. The dependent variable is the municipality specific PAL treatment effect. We restrict the sample to the 5th-95th percentile of this variable in order to reduce the influence of outliers. The first and third columns include all observations meeting the stated criteria. In the second and fourth columns, we remove all municipalities within, or that contain, cities with $>500,000$ (see main text), as these areas already had high penetrance of chlorinated water prior to PAL. All models include municipality level controls from the 1990 census, including the \% of population completing secondary education, average logged household income, and \% indigenous population. Robust standard errors are in parenthesis. Appendix Table 6 demonstrates the robustness of the findings to the inclusion of baseline diarrheal disease mortality rates (averaged between 1986-1990) and state fixed effects. 
Table 5: Behavioral Responses: Expenditures on Soaps, Detergents, Bottled Water

\begin{tabular}{lccc}
\hline & Full Sample & $\begin{array}{c}\text { Small/Medium } \\
\text { Sized Cities }\end{array}$ & Large Cities \\
\hline 1(Post)*Base Diarrhea & -0.011 & -0.017 & -0.0004 \\
& $(0.013)$ & $(0.0074)$ & $(0.025)$ \\
& {$[0.52]$} & {$[0.13]$} & {$[0.97]$} \\
N & & & \\
R-squared & 32,119 & 21,385 & 10,734 \\
\hline
\end{tabular}

Notes: Estimates of Equation 4 from the main text. Robust standard errors, correcting for clustering at the state level, are in parenthesis. Each column represents a separate regression, with the column header denoting the specific sub-sample of interest. Because there are only 32 states, we additionally compute cluster wild bootstrap-t corrected p-values for the coefficient of interest (Cameron et al., 2008), which are provided in the square brackets. The dependent variable is the inverse hyperbolic sine transformation of expenditures on soaps, detergents, and bottled/mineral water. All models include controls Post $\times$ Baseline Respiratory Disease, age, sex, and education of the household head, household size, and logged household total income, as well as state and survey rear FE. The main coefficient of interest is on $\mathbf{1}$ (Post) $\times$ Base Diarrhea, where Baseline Diarrhea is the average under-5 diarrheal mortality rate over 1988-1990. To interpret the results, focusing on the second column an interquartile decrease in diarrheal mortality (about 4 deaths per 1,000 live births) was associated with a $6.7 \%$ decrease in soap, detergent, and bottled water expenditures. Appendix Table 8 breaks down the estimates in the second column by soaps and detergents versus bottled/mineral water, respectively. 


\section{Table 6: Cost Effectiveness}

\begin{tabular}{lcccc}
\hline Estimate & $\begin{array}{c}\text { Under-5 Deaths } \\
\text { Averted }\end{array}$ & $\begin{array}{c}\text { Program Cost } \\
\text { (2015 USD) }\end{array}$ & $\begin{array}{c}\text { Cost/Death Averted } \\
\text { (2015 USD) }\end{array}$ & $\begin{array}{c}\text { Cost/Life Year } \\
\text { Saved (2015 USD) }\end{array}$ \\
\hline Point & 28190 & 1.86 billion & 65981 & 1100 \\
Lower 95\% CI & 19654 & 1.86 billion & 94637 & 1577 \\
Upper 95\% CI & 34437 & 1.86 billion & 54012 & 900 \\
\hline
\end{tabular}

Notes: 2.2 million live births occurred each year between 1985-1990 in small and medium-sized

municipalities. We use this figure, the pre-intervention average baseline mortality rate, and estimates from Col 2 of Table 2 to calculate the number of under-5 deaths averted each year between 1991-1995. We do this using both the point estimates from the model, as well as the lower and upper $95 \%$ CI. The column "Under-5 Deaths Averted" displays these estimates. The total program cost over this period comes from administrative sources. The cost per death averted is simply the total cost/\# of deaths averted. To calculate Cost/Life Year Saved, we assume each under-5 child whose death was averted would (conservatively) live to the age of 60 (and so we multiply the numbers in the penultimate column by 60 to get the numbers in the last column). All costs are expressed in 2015 USD. 


\title{
APPENDIX
}

Urban Water Disinfection and Mortality Decline in Developing Countries

\author{
Sonia R. Bhalotra \\ Alberto Diaz-Cayeros \\ Grant Miller \\ Alfonso Miranda \\ Atheendar S. Venkataramani
}




\section{Appendix Figure 1: National Trends in Under-5 Deaths by Cause, 1979-1997}

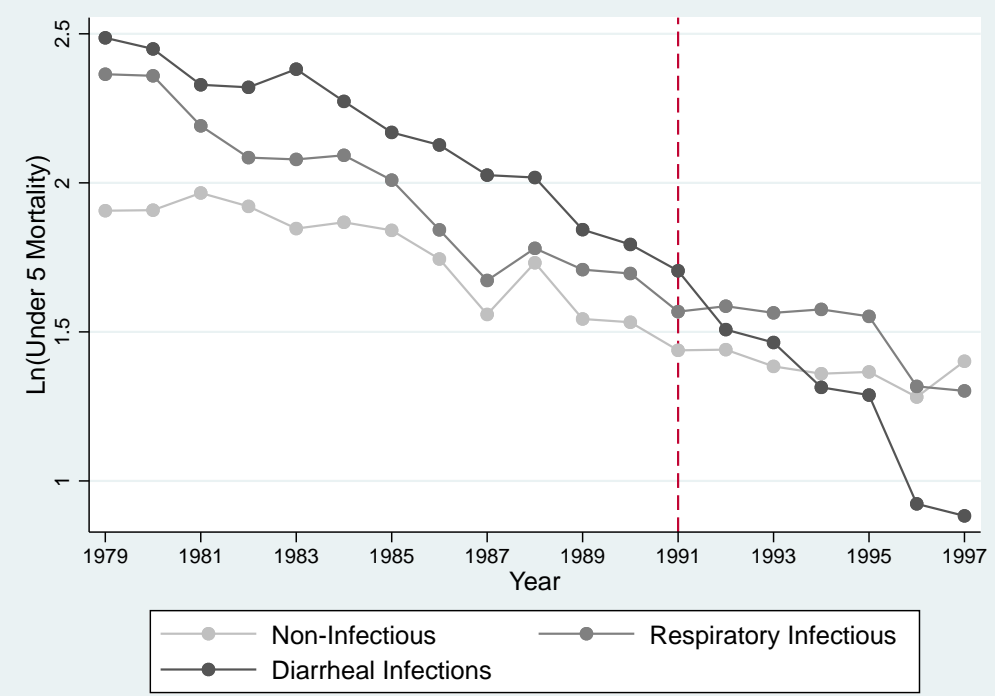

Source: Mexican Vital Statistics. Unlike Figure 3, we plot (logged) number of deaths instead of deaths rate here because municipality specific live births were not available prior to 1985 .

\section{Appendix Figure 2: Convergence in Diarrheal Mortality Rates}

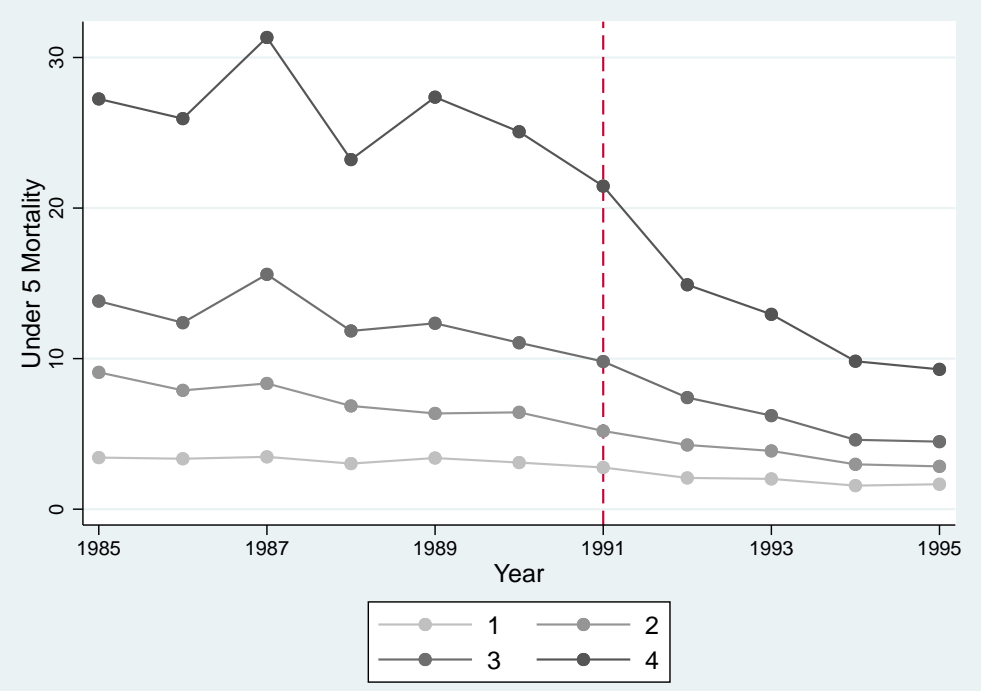

Source: Mexican Vital Statistics. Figure plots trends in under-5 diarrheal mortality rates by quartile of (state) pre-intervention diarrheal mortality (calculated as the average over 1988-1990). The figure demonstrates rapid convergence starting in 1991. 


\section{Appendix Table 1: DID Trend Break Models: Inclusion of State-Year FE}

\begin{tabular}{lcc}
\hline & $\begin{array}{c}\text { Respiratory } \\
\text { Infection Control }\end{array}$ & $\begin{array}{c}\text { Non-Infectious } \\
\text { Childhood Disease } \\
\text { Control }\end{array}$ \\
\hline 1(Diarrhea)*1(Post) & -0.086 & -0.143 \\
& $(0.037)$ & $(0.036)$ \\
1(Diarrhea)*1(Post)*Year & -0.121 & -0.101 \\
& $(0.013)$ & $(0.013)$ \\
N & & \\
R-squared & 30,800 & 30,767 \\
\% Decline by 1995 Due to PAL & 0.50 & 0.49 \\
\hline
\end{tabular}

Notes: Estimates of Equation 2 from the main text. Models are identical to those presented in Table 2 except here we include state-year level fixed effects. The final row, \% Decline by 1995 Due to PAL is calculated by adding the coefficient on the level break to four times that on the trend break (since 1995 is 4 years after PAL). The year variable is rescaled such that $1991=0$ and increments above and below are denoted by positive and negative integers. See Table 2 notes for further details.

\section{Appendix Table 2: DID Trend Break Models: Annual Death Counts}

\begin{tabular}{lcc}
\hline & $\begin{array}{c}\text { Respiratory } \\
\text { Infection Control }\end{array}$ & $\begin{array}{c}\text { Non-Infectious } \\
\text { Childhood Disease } \\
\text { Control }\end{array}$ \\
\hline 1(Diarrhea)*1(Post) & -0.0509 & -0.0860 \\
& $(0.0206)$ & $(0.0250)$ \\
1(Diarrhea)*1(Post)*Year & -0.134 & -0.101 \\
& $(0.009)$ & $(0.0010)$ \\
N & 30,800 & 30,767 \\
\% Decline by 1995 Due to PAL & $-59 \%$ & $-49 \%$ \\
\hline
\end{tabular}

Notes: This table is identical to Table 2 in the main text except here we data on death counts between 1985-1995. We use a negative binomial model to model the number of deaths, and present incidence rate ratios (IRR), which we use to calculate the percent relative decline in diarrheal deaths. Robust standard errors, correcting for clustering at the municipality level, in parenthesis. 


\section{Appendix Table 3: DID Trend Break Models: Municipalities, 1979-1997}

\begin{tabular}{lcc}
\hline & $\begin{array}{c}\text { Respiratory } \\
\text { Infection Control }\end{array}$ & $\begin{array}{c}\text { Non-Infectious } \\
\text { Childhood } \\
\text { Disease Control }\end{array}$ \\
\hline 1(Diarrhea)*1(Post) & -0.203 & 0.00509 \\
& $(0.0215)$ & $(0.0219)$ \\
1(Diarrhea)*1(Post)*Year & -0.136 & -0.158 \\
& $(0.00543)$ & $(0.00563)$ \\
N & 51,870 & 51,870 \\
R-squared & 0.77 & 0.78 \\
\% Decline by 1995 Due to PAL & $-75 \%$ & $-64 \%$ \\
\hline
\end{tabular}

Notes: Estimates of Equation 2 from the main text. This table is identical to Table 2 in the main text except here we use data from 1979-1997, instead of restricting the sample to 1985-1995. The dependent variable is the inverse hyperbolic sine transform of the number of deaths under age 5 (we do not examine mortality rates since municipality specific births data was not available during the early part of the time period). Robust standard errors, correcting for clustering at the municipality level, are in parenthesis. 


\section{Appendix Table 4: Diarrheal Mortality Decline and In-Migration}

\begin{tabular}{lccc} 
& $(1)$ & $(2)$ & $(3)$ \\
\hline$\Delta$ Diarrhea & & & \\
& $0.13^{*}$ & 0.055 & 0.082 \\
& $(0.07)$ & $(0.057)$ & $(0.065)$ \\
$\mathrm{N}$ & & & \\
$\mathrm{R}$-squared & 627 & 627 & 627 \\
& 0.018 & 0.14 & 0.23 \\
& & & \\
BaseDiar & $-0.10^{* *}$ & -0.033 & -0.042 \\
& $(0.047)$ & $(0.043)$ & $(0.042)$ \\
N & & & \\
R-squared & 627 & 627 & 627 \\
& 0.02 & 0.14 & 0.23 \\
\hline Controls & & & \\
\hline Municipality SES (Education) & No & Yes & No \\
State FE & No & No & Yes \\
\hline
\end{tabular}

Notes: To assess potential non-random migration as a function of exposure to PAL, we use data from the public use 1995 Mexican Population Census Microdata, a representative 1.5\% sample which allows us to identify individuals who lived in a different municipality 5 years prior to survey (i.e., pre-PAL, which was in 1991). In prior censuses, only interstate migration is identifiable. The identity of the municipality the individual moved from is not known, though the current municipality of residence is recorded. Focus on reproductive age adults (i.e., men and women ages 18-40), we can construct the in-migration rate for each municipality (in our data we can identify nearly 700 municipalities). On average, the share of individuals living in a given municipality who migrated from elsewhere over the preceding 5 -year period was $11.1 \%$. To assess whether in-migration responded to changes in diarrheal disease environment, we estimated models of the following form:

$$
\text { Migration }_{i j}=\alpha_{0}+\alpha_{l}\left(\Delta \text { Diarrhea }_{j}\right)+\boldsymbol{X}_{(i)(j)}+u_{i j t}
$$

And:

$$
\text { Migration }_{i j}=\alpha_{0}+\alpha_{l}\left(\text { BaseDiar }_{j}\right)+\boldsymbol{X}_{(i)(j)}+u_{i j t}
$$

Here, $i$ represents the municipality and $j$ the state. Migration $i j$ is the proportion of individuals in a given county in 1995 who lived in another county 5 years prior; $\Delta$ Diarrhe $_{j}$ is the change in under-5 diarrheal disease mortality in the post versus pre-periods; BaseDiar $_{j}$ is pre-intervention baseline diarrheal mortality rate change; and $\boldsymbol{X}_{(i)(j)}$ represent municipality specific, preintervention controls and/or state-fixed effects. The first regression assesses whether in-migration changed as a function of the degree of decline in diarrheal mortality. The second regression leverages the insight that areas with higher pre-intervention diarrheal mortality rates gained more from PAL (see Section 6 and Appendix Table 6). In models without municipality controls and state fixed effects (col 1), we find that areas with larger declines in diarrheal mortality, or stood to gain more from PAL, actually had lower proportions of in-migrants. The estimates suggest that the average drop in diarrheal mortality pre-post PAL was associated with a $1.3 \%$ pt decrease in the proportion of in-migrants. However, once we control for municipality education or state fixed effects (col 2 and 3, respectively), these associations disappear entirely. We conclude that nonrandom migration is unlikely to be driving our findings. 


\section{Appendix Table 5: Heterogeneity Analysis, Robustness to Additional Covariates}

\begin{tabular}{|c|c|c|c|c|c|c|c|c|}
\hline & Full Sample & $\begin{array}{c}\text { Exclude Large } \\
\text { Cities } \\
\end{array}$ & Full Sample & $\begin{array}{c}\text { Exclude Large } \\
\text { Cities }\end{array}$ & Full Sample & $\begin{array}{c}\text { Exclude Large } \\
\text { Cities } \\
\end{array}$ & Full Sample & $\begin{array}{c}\text { Exclude Large } \\
\text { Cities }\end{array}$ \\
\hline$\%$ HH with Access to Piped Water & $\begin{array}{l}-0.142 \\
(0.304)\end{array}$ & $\begin{array}{l}-0.112 \\
(0.317)\end{array}$ & $\begin{array}{l}-0.0694 \\
(0.309)\end{array}$ & $\begin{array}{l}-0.0366 \\
(0.322)\end{array}$ & $\begin{array}{c}0.228 \\
(0.357)\end{array}$ & $\begin{array}{c}0.260 \\
(0.375)\end{array}$ & $\begin{array}{c}0.277 \\
(0.364)\end{array}$ & $\begin{array}{c}0.305 \\
(0.381)\end{array}$ \\
\hline$\%$ HH with Access to Sewage System & $\begin{array}{l}-0.548 \\
(0.326)\end{array}$ & $\begin{array}{l}-0.599 \\
(0.340)\end{array}$ & $\begin{array}{l}-0.689 \\
(0.336)\end{array}$ & $\begin{array}{l}-0.763 \\
(0.353)\end{array}$ & $\begin{array}{l}-0.752 \\
(0.413)\end{array}$ & $\begin{array}{l}-0.784 \\
(0.435)\end{array}$ & $\begin{array}{l}-0.856 \\
(0.421)\end{array}$ & $\begin{array}{l}-0.893 \\
(0.444)\end{array}$ \\
\hline Piped Water Coverage Ratio (1960/1990) & & & $\begin{array}{c}0.386 \\
(0.227)\end{array}$ & $\begin{array}{c}0.46 \\
(0.253)\end{array}$ & & & $\begin{array}{c}0.326 \\
(0.238)\end{array}$ & $\begin{array}{c}0.364 \\
(0.264)\end{array}$ \\
\hline $\begin{array}{l}\text { Additional Controls } \\
\text { Baseline Diarrheal Mortality }\end{array}$ & & & & & & & & \\
\hline $\begin{array}{l}\text { Baseline Diarrheal Mortality } \\
\text { State Fixed Effects }\end{array}$ & $\begin{array}{l}\text { Yes } \\
\text { No }\end{array}$ & $\begin{array}{l}\text { Yes } \\
\text { No }\end{array}$ & $\begin{array}{l}\text { Yes } \\
\text { No }\end{array}$ & $\begin{array}{l}\text { Yes } \\
\text { No }\end{array}$ & $\begin{array}{l}\text { Yes } \\
\text { Yes }\end{array}$ & $\begin{array}{l}\text { Yes } \\
\text { Yes }\end{array}$ & $\begin{array}{l}\text { Yes } \\
\text { Yes }\end{array}$ & $\begin{array}{l}\text { Yes } \\
\text { Yes }\end{array}$ \\
\hline $\begin{array}{l}\mathrm{N} \\
\mathrm{R} \text {-squared }\end{array}$ & $\begin{array}{l}1,041 \\
0.020\end{array}$ & $\begin{array}{c}968 \\
0.020\end{array}$ & $\begin{array}{l}1,041 \\
0.023\end{array}$ & $\begin{array}{c}968 \\
0.023\end{array}$ & $\begin{array}{l}1,041 \\
0.059\end{array}$ & $\begin{array}{c}968 \\
0.059\end{array}$ & $\begin{array}{l}1,041 \\
0.061\end{array}$ & $\begin{array}{c}968 \\
0.061\end{array}$ \\
\hline
\end{tabular}

Notes: Models are identical to those presented in Table 4, except here we additionally adjust for pre-PAL average diarrheal mortality between 1986-1990 (first four columns) and state fixed effects (last four columns). 


\section{Appendix Table 6: Convergence}

\begin{tabular}{lcccc}
\hline & $(1)$ & $(2)$ & $(3)$ & $(4)$ \\
\hline & Level & IHSine & Level & IHSine \\
\hline $\mathbf{1}$ (Post)*Base Diarrhea & -0.596 & -0.0194 & -0.246 & -0.00799 \\
& $(0.0215)$ & $(0.00440)$ & $(0.0446)$ & $(0.00286)$ \\
Base Diarrhea*Year & & & & \\
& & & -0.0576 & -0.00609 \\
& & & $(0.0120)$ & $(0.00152)$ \\
1(Post)*Base Diarrhea*Year & & & -0.0426 & 0.000134 \\
& & & $0.00801)$ & $(0.000494)$ \\
N & & & & \\
R-squared & 15,444 & 15,444 & 15,444 & 15,444 \\
\hline
\end{tabular}

Notes: Estimates provided are versions of the model:

$$
M_{i j t}=\alpha_{0}+\alpha_{l}\left(\text { Post }_{t} \times \text { Base_Diarrhea } j\right)+\lambda_{j}+\theta_{t}+u_{i j t}
$$

where $M_{i j t}=$ the municipality-specific mortality rate, Base_diarrhea refers to the baseline under-5 diarrheal mortality rate (average for each municipality over 1986-1990), Post $=1$ for years 1991 and thereafter, and the remainder of the variables reflect state and year fixed effects. Estimating using logged mortality rates as the dependent variable evidence of relative convergence, whereas estimates using levels recover absolute convergence. A negative coefficient on post*base (and would imply convergence. Columns 3 and 4 decompose this convergence into a level and trend break. The 1985-1995 state-level sample is used for all regressions ( $\mathrm{N}$ reflects the number of stateyears). 


\section{Appendix Table 7: Behavioral Responses, Disaggregated by Spending Category}

\begin{tabular}{lcc}
\hline & Soaps+Detergents & $\begin{array}{c}\text { Bottled/Mineral } \\
\text { Water }\end{array}$ \\
\hline 1(Post)*Base Diarrhea & -0.023 & 0.018 \\
& $(0.009)$ & $(0.020)$ \\
& {$[0.08]$} & {$[0.45]$} \\
N & 21,385 & 21,385 \\
R-squared & 0.88 & 0.11 \\
\hline
\end{tabular}

Notes: Models are identical to those estimated in Col 2 of Table 5 except here we disaggregate spending on soaps and detergents from bottled or mineral water. Robust standard errors, correcting for clustering at the state level, are in parenthesis. Each column represents a separate regression, with the column header denoting the specific sub-sample of interest. Because there are only 32 states, we additionally compute cluster wild bootstrap-t corrected p-values for the coefficient of interest (Cameron et al., 2008), which are provided in the square brackets. All dependent variables are transformed by the inverse hyperbolic sine. 